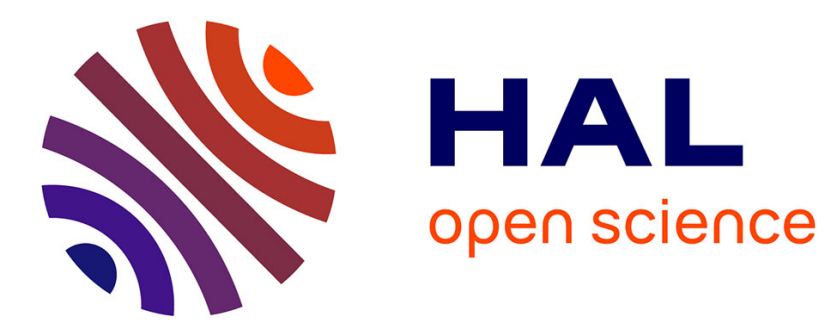

\title{
A dual pore carbon aerogel based air cathode for a highly rechargeable lithium-air battery
}

Fang Wang, Yang-Hai Xu, Zhong-Kuan Luo, Yan Pang, Chun-Sheng Liang, Jing Chen, Dong Liu, Xianghua Zhang

\section{- To cite this version:}

Fang Wang, Yang-Hai Xu, Zhong-Kuan Luo, Yan Pang, Chun-Sheng Liang, et al.. A dual pore carbon aerogel based air cathode for a highly rechargeable lithium-air battery. Journal of Power Sources, 2014, 272, pp.1061 - 1071. 10.1016/j.jpowsour.2014.08.126 . hal-01072731

\section{HAL Id: hal-01072731 https://hal.science/hal-01072731}

Submitted on 8 Oct 2014

HAL is a multi-disciplinary open access archive for the deposit and dissemination of scientific research documents, whether they are published or not. The documents may come from teaching and research institutions in France or abroad, or from public or private research centers.
L'archive ouverte pluridisciplinaire HAL, est destinée au dépôt et à la diffusion de documents scientifiques de niveau recherche, publiés ou non, émanant des établissements d'enseignement et de recherche français ou étrangers, des laboratoires publics ou privés. 
The table of contents entry should be 50-60 words long, and the first phrase should be bold. A highly conductive dual pore carbon aerogel air cathode is successfully synthesized, favorable for the fast mass transport and superior discharged products accommodation/decomposition, thus realizing a relatively high discharge rate cycling performance and impaired cathode passivation. This work targets for exploiting a high power and reversible lithium-air battery by coordinating the necessary ingredients: carbon loading and current density et al..

Keyword: lithium-air battery, carbon aerogel, dual pore structure, cathode passivation, sulfolane

Fang Wang ${ }^{\text {a, }}$, Yang-Hai X u ${ }^{\text {a }}$, Zhong-Kuan Luo ${ }^{\text {a, b, * }}$, Yan Pang ${ }^{\text {a }}$, Chun-Sheng Liang ${ }^{\text {, }}$ Jing Chen ${ }^{a}$, Dong Liu ${ }^{\mathrm{a}}$, Xiang-hua Zhang ${ }^{\text {a,c }}$

Title: A dual pore carbon aerogel based air cathode for a highly rechargeable lithium-air battery

ToC figure (Image size: Please provide an image with a minimum of $531 \times 1328$ pixels $(\mathrm{h} \times$ w) or proportionally more. The image should be readable at a size of $5 \times 13 \mathrm{~cm}$ using a regular screen resolution of $96 \mathrm{dpi}$.)

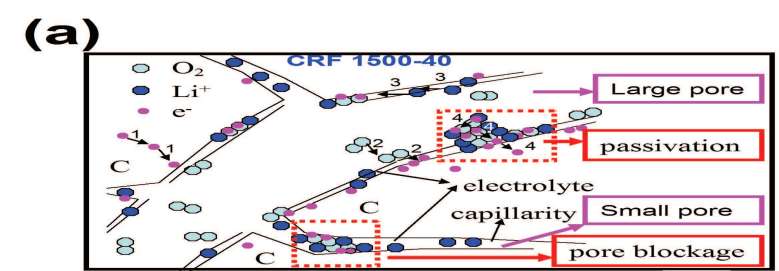

(c)

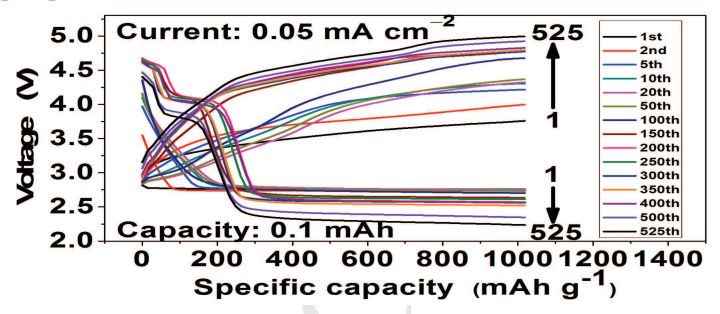

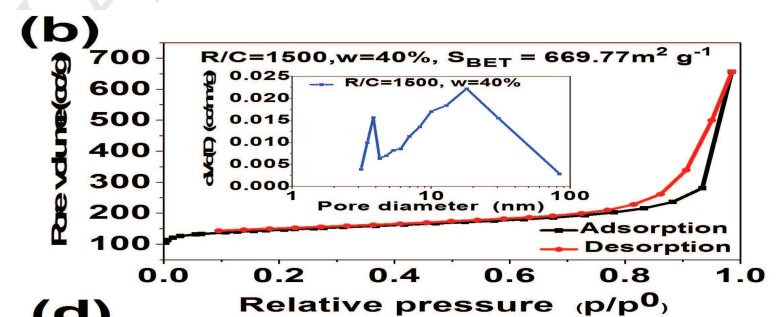

(d)

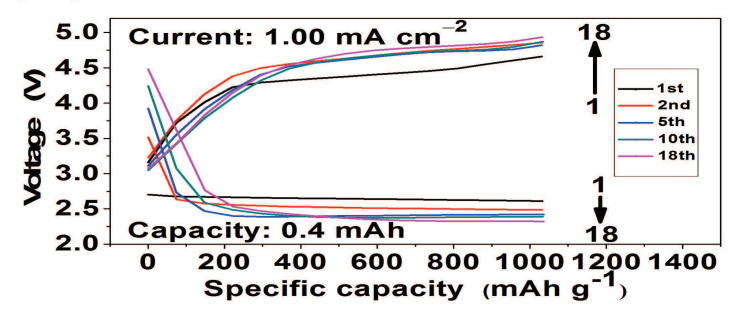




\section{A dual pore carbon aerogel based air cathode for a highly rechargeable}

\section{lithium-air battery}

Fang Wang ${ }^{\text {a, }}$, Yang-Hai Xu ${ }^{\mathrm{a}}$, Zhong-Kuan Luo ${ }^{\mathrm{a}, \mathrm{b},{ }^{*}, \text { Yan Pang }}{ }^{\mathrm{a}}$, Chun-Sheng Liang ${ }^{\mathrm{a}}$, Jing Chen ${ }^{\mathrm{a}}$, Dong Liu ${ }^{\mathrm{a}}$, Xiang-hua Zhang ${ }^{\text {a,c }}$

${ }^{a}$ College of Chemistry and Chemical Engineering, Shenzhen University, China.

${ }^{b}$ Zhejiang California International NanoSystems Institute \& Department of Materials Science and Engineering, Zhejiang University, China.

${ }^{c}$ Laboratory of glasses and Ceramics, UMR CNRS 6226 "Institut des Sciences

Chimiques de Rennes", Université de Rennes I, 35042 Rennes, France.

"Corresponding author. Tel.: +86 755 26557249; Fax: +8675526536141.

E-mail: wangfsz@szu.edu.cn (Prof.FangWang); lzk@szu.edu.cn (Prof. Zhong-Kuan Luo)

Postal address: 3688 Nanhai Avenue, Nanshan District, Shenzhen 518060, China.

\section{H I G H L I G H T S}

- Carbon aerogel's dual-pore enables mass transport in two separate channels.

- Low carbon loading cathode is favorable for lithium-air batteries' reversibility.

- A current density between 0.10 and $0.20 \mathrm{~mA} \mathrm{~cm}^{-2}$ contributes to better cyclability.

\section{A B S T R A C T}

Cathode structure plays a vital role in lithium-air battery for that it can provide space for discharged products accommodation and free path for oxygen, $\mathrm{e}^{-}$and $\mathrm{Li}^{+}$transport. 
However, pore blockage, cathode passivation and degradation all result in low discharge rates and poor cycling capability. To get rid of these predicaments, a novel highly conductive dual pore carbon aerogel based air cathode is fabricated to construct a lithium-air battery, which exhibits 18 to 525 cycles in the LiTFSI/sulfolane electrolyte at a current density varying from $1.00 \mathrm{~mA} \mathrm{~cm}^{-2}$ to 0.05 $\mathrm{mA} \mathrm{cm}{ }^{-2}$, accompanied by a high energy efficiency of $78.32 \%$. We postulate that the essence lies in that the as-prepared air cathode inventively create a suitable tri-phase boundary reaction zone, facilitating oxygen and $\mathrm{Li}^{+}$diffusion in two independant pore channels, thus realizing a relative higher discharge rate capability, lower pore blockage and cathode passivation. Further, pore structure, carbon loading, rate capability, discharge depth and the air's effect are exploited and coordinated, targeting for a high power and reversible lithium-air battery. Such nano-porous carbon aerogel air cathode of novel dual pore structure and material design is expected to be an attractive alternative for lithium-air batteries and other lithium based batteries.

Keywords: lithium-air battery, carbon aerogel, dual pore structure, cathode passivation, sulfolane

\section{Introduction}

Lithium-air battery, with a high energy density of $1000 \mathrm{Wh} \mathrm{kg}^{-1}$ which is $2-4$ times higher than that of current state-of-art lithium-ion battery, has attracted unprecedentedly broad attention and is destined to be further developed to address series of problems, such as the finite oil resources, deteriorated climate and high fuel prices, and to meet the demand of long distance transport's energy storage in electric 
vehicle industry [1-3]. A typical non-aqueous rechargeable lithium-air battery involves reversible formation/decomposition of $\mathrm{Li}_{2} \mathrm{O}_{2}$ via multiple discharge-charge cycles. However, despite such unmatched potential superiority, pore blockage, cathode passivation and degradation all result in low discharge rates and poor cycling stability (about 100 cycles), restricting its practical utilization [2-15].

To build a reversible and long-life span lithium-air battery, cathode design is an indispensable task as well as challenge. Since cathode has function of accommodating discharge products and providing free path for oxygen, $\mathrm{e}^{-}$and $\mathrm{Li}^{+}$transport, the porous structure is a prerequisite and highlighted. What's more, requirements like high conductivity, low cost and ease of fabrication all render carbon one of the most attractive materials for constructing a porous (three-dimensional) electrode. In order to achieve an optimum performance, various carbon sources (with surface defects and functional groups, hydrophobicity/hydrophilicity and oxygen adsorption of the carbon surface et al.), specific surface area, pore volume, pore size distribution and mass density must be all considered and synergistic, at last to get a compromise. Though lots of efforts have been spared in optimizing the cathode structure, pore blockage, cathode passivation and degradation are still encountered [16-26].

Inspired by Zhang et al. [23, 27-28], a novel highly conductive nano-porous carbon aerogel comprising of fine dual pore structure was successfully fabricated here to improve the mass transport and to reduce pore blockage and cathode passivation. For such type battery, we postulate that the large pore is apt to facilitate oxygen penetration, and simultaneously yield and store discharged products at its abundant 
catalytically active carbon surface; while the small pore with little or non-catalytic active centre will be filled with highly conductive $\mathrm{Li}^{+}$electrolyte due to the coalition of hydrophilic carbon surface and capillary pressure, conducive to $\mathrm{Li}^{+}$transfer. By this new approach of cathodes designing, high oxygen-transport properties and degenerative pore blockage will be realized, favorable for the high discharge rate performance and cyclability. Free charges $\left(\mathrm{e}^{-}\right)$will mainly transfer to tri-phase boundary reaction zones where accumulates higher oxygen concentration, through carbon aerogel's highly conductive interconnected 3D network. Meanwhile, electro-active material's high specific surface area can provide more reaction sites for electrochemical reaction and its large pore volume renders large space for discharged products accommodation. Li-oxide precipitation will be eventually filled in the pores which house a catalytic active junction (with an enormous amount of both $\mathrm{O}_{2}$ and $\mathrm{Li}^{+}$, complementary subsystems) $[24,25]$.

$1 \mathrm{M} \mathrm{LiTFSI} /$ sulfolane was chosen as electrolyte for its relative stability which was previously testified by Zhang and our group et al. [29-36]. For this newly built battery system, when controlling the specific capacity of $1000 \mathrm{mAh} \mathrm{g}{ }^{-1}, 525$ cycles and 112 cycles were obtained at a current density of $0.05 \mathrm{~mA} \mathrm{~cm}^{-2}$ and $0.10 \mathrm{~mA} \mathrm{~cm}^{-2}$, respectively, which far exceeds that of the previous researches that identically adopted carbon aerogel as air electrode active materials [37-43]. Such impressive cycling behavior can be attributed to the distinctive battery structure which includes both the well modified cathode structure and relatively stable electrolyte, certainly in addition to an oxygen filled environment and the effective control of discharge rates and depth. 
As compared to common used carbonate, ester, dimethylformamide and ether-based electrolyte [44-49], sulfolane-based electrolyte could endure high overpotential during charge process and thus shows superior antioxidant ability which is bound to obtain a relatively stable $\mathrm{Li}_{-} \mathrm{O}_{2}$ battery. Following the carefully controlling of the discharge rates and depth, granular to sheet-shaped or layered lithium peroxides (unlike bulk precipitates) which could undermine the cathode passivation formed during discharge process, and had already been proved to be metallic in certain lattice surface [50-55].

\section{Experimental}

2.1. Preparation of carbon aerogel and cathode, and cell assembling/disassembling

Carbon aerogel was taken as the cathode active materials here due to its light density, high specific surface area, good conductivity as well as its wide scale of pore size distribution. It was synthesized according to a resorcinol-formaldehyde (R-F) polycondensation and carbonization method previously reported by Richard W. Pekala [37]. After successful preparation, it was mixed with $\mathrm{pVdF}$ powder in a molar ratio of 9:1 and stirred in a NMP containing bottle to make approriate viscous slurry, which was soon deposited on carbon paper to make various air cathodes, where the aerogel coating was applied as a layer on one side of the carbon paper. Here, cathodes with different carbon loading ranging from $0.1 \mathrm{mg}$ to $0.6 \mathrm{mg}$ were obtained. The aerogel loading also can be shown in the unit of $\mathrm{m} \mathrm{cm}^{-2}$, which was in the range of $0.057 \mathrm{mg} \mathrm{cm}{ }^{-2}$ to $0.340 \mathrm{mg} \mathrm{cm}^{-2}$. Hereafter, with a whatman GF/D glassy fiber 
separator and $1 \mathrm{M} \mathrm{LiTFSI/sulfolane} \mathrm{electrolyte,} \mathrm{the} \mathrm{lithium-air} \mathrm{batteries} \mathrm{were}$ assembled in a glove box with moisture and oxygen concentration lower than 0.5 ppm. The schematic diagram of the lithium-air battery model (CR2032) can be seen in Fig. S1. Then the cells were aged for $12 \mathrm{~h}$ in an inert atmosphere and exposed to oxygen for more than $30 \mathrm{~min}$ prior to electrochemical test. The boundaries were chosen according to both the literature and our previous experimental (see details in the Supporting Information). Intermittently, the batteries of different discharge or charge state were disassembled in the glove box. After DME solution soaking and vacuum drying for another $12 \mathrm{~h}$, the cathode was sealed quickly in a gas-tight device for the subsequent XRD and SEM test.

2.2. Materials characterization and electro-chemical measurements

SEM and TEM tests were exploited to analyze the morphology of the synthesized RF aerogel and carbon aerogel, as well as the discharged/charged products. The TG-DTA test was used to evaluate the RF aerogel's thermal stability and ensure the degassing temperature for the following $\mathrm{N}_{2}$ absorption/desorption test which aimed at studying the specific surface area, the BJH pore size distribution and pore volume. Here, XRD test was adopted to inquire the discharged and charged products composition and investigate the mechanism of oxygen reduction reaction (ORR) and oxygen evolution reaction (OER) in lithium-air batteries. The standard electrical four-probe method was utilized to check the cathode and carbon aerogel's electrical conductivity.

With regard to electrochemical measurement, galvanostatic charge/discharge test, 
CV test and electrochemical impedance analysis were all performed to examine the cycling stability and cycling life, the dynamic process of the inner electrochemical reaction and mechanism, respectively. All the cycling numbers were recorded under the cut off voltage of $5.0 \mathrm{~V}$ for charge or above $2.0 \mathrm{~V}$ for discharge with fixed specific capacities or capacities. The discharge time is controlled to be $2.3 \mathrm{~h}$ simultaneously when the current density surpasses $0.10 \mathrm{~mA} \mathrm{~cm}^{-2}$, which aims at obtaining a practical use. It's highlighted here that the specific capacity is presented as capacity per gram of carbon, which would be convenient for comparison to previous work, however it probably grossly inflates the practical capacity available. The cell voltage gap is taken from the number of $60 \%$ specific capacity (600 for $1000 \mathrm{mAh} \mathrm{g}^{-1}$ or 1200 for 2000 $\mathrm{mAh} \mathrm{g}^{-1}$ et al.). Detailed fabricating and testing method or process were illustrated in the Supporting Information.

\section{Results and discussion}

\subsection{Materials fabrication and characterization}

\subsubsection{Morphology of organic aerogel and carbon aerogel}

Organic aerogel and carbon aerogel are synthesized through a series of complex physical and chemical processes, including sol-gel reaction, solvent exchange and nbsphigh sintering. By carefully controlling the molar ratio of resorcinol (R) to sodium carbonate $(\mathrm{C})$ and the reactant mass fraction (w), various controllable pore structures varying from micron to nanometer level can be made. As can be seen in Fig. 1(a), numerous spherical-like particles aggregate to large cross-linked spatial 3D 
network structure for organic aerogel (RF1500-40). After calcination, it turns to carbon aerogel (CRF1500-40) and exhibits much loose state and full of nano-scale pores at the external surface (Fig. 1(b)). The TEM graphs of RF aerogel (Fig. 1(c), RF1500-40) and carbon aerogel (Fig. 1(d), CRF1500-40) also show uniform spherical particles about $100 \mathrm{~nm}$ and a great number of interconnected mesopores. The puffy carbon aerogel, with a low density, not only decreases the cathode coating materials mass but also provides large volume for discharge products to be accommodated. Meanwhile, these rich pores must be convenient passages for the outside gas and anode $\mathrm{Li}^{+}$to get through electrolyte to the carbon active areas.
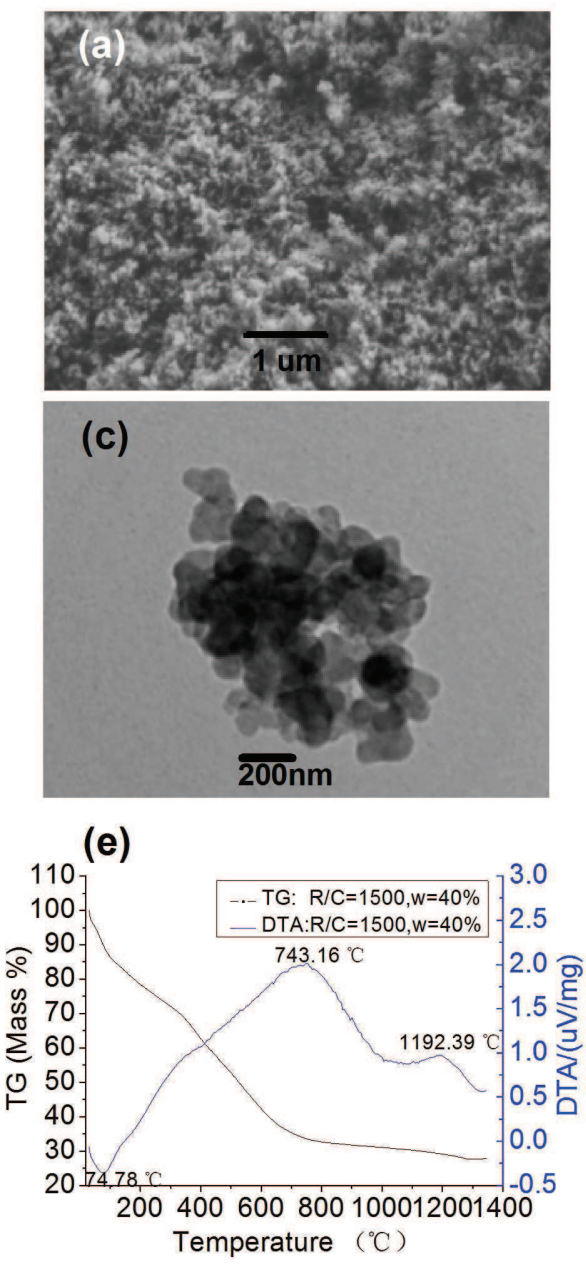
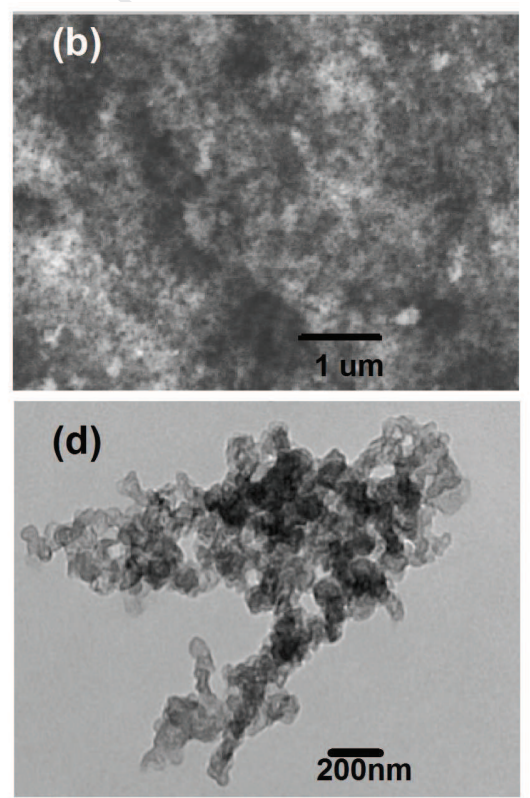

(f)

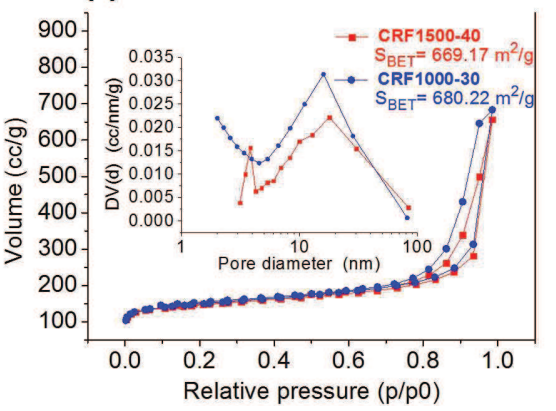

Fig. 1. Morphology of the RF aerogel $(a, c)$ and carbon aerogel $(b, d)$ and RF 
aerogel's thermal stability (e) and carbon aerogels' pore size distribution (f).The FE-SEM and TEM images are all collected at a magnification of 20,000 and 93,000, respectively; Fig. 1(e) Thermogravimetric analysis and derivative thermogravimetry of a dried RF aerogel; (f) $\mathrm{N}_{2}$ adsorption-desorption isotherms at $77 \mathrm{~K}$ for carbon aerogels and their inset BJH pore size distribution graphs.

\subsubsection{Thermal stability of the RF aerogel}

TG-DTA analysis is performed to explore the appropriate calcination temperature. There are two exothermic peaks and an endothermic peak in the Fig. 1 (e), corresponding to the benzene ring fracture, $\mathrm{C}-\mathrm{H}$ bond split and water loss, respectively. The fracture of these bonds generates more meso-pores, promoting the transformation of macro-pores and closed pores into meso-pores and micropores. Thus pores are greatly rich in the aerogels and the specific surface area is higher after calcination. It is also noted that the mass loss of the RF aerogel remains stable or is slowing down at temperature above $800{ }^{\circ} \mathrm{C}$ from the TG curve. In theory, higher temperature will contribute to higher conductivity at the expense of consuming more power sources. Therefore, a moderate temperature of $1050{ }^{\circ} \mathrm{C}$ is chosen, and a carbonized material yield of $27.8 \%$ is gained, with a superior conductivity of $1.218 \mathrm{~S}$ $\mathrm{cm}^{-1}$. Such high conductivity, convenient for fast charge transfer in the interconnected spatial 3D network, is enough to maintain good electrochemical reaction in the lithium-air batteries

\subsubsection{BET surface area and BJH pore size distribution of carbon aerogel}

Carbon aerogels (see Fig. S2, Fig. S3) with different pore structure were 
synthesized by using the sol-gel method. As is shown in Fig. 1(f), two kinds of carbon aerogels, CRF1000-30 and CRF1500-40, with characteristic single and dual pore size distribution, especially possessing extremely similar average mesopore diameter around $8.0 \mathrm{~nm}$, exhibit type-IV isotherms following the IUPAC classification. Particularly, there exist hysteresis loops at the high relative pressure above 0.8 , indicating the presence of a great number of meso-pores. It is known that meso-pore favors mass transport and enlarges reaction active sites, facilitating the reaction kinetics and possibility. What's more, the apparent dual-pore structure which emerges in the carbon's meso-pore scope and primarily concentrates at pore width of $3.85 \mathrm{~nm}$ and $17.95 \mathrm{~nm}$ can effectively diminish blockage stemming from the deposited discharge products and provide free path for the oxygen and $\mathrm{Li}^{+}$. Table 1 and Table S1 provide detailed porosity parameters of the carbon aerogel samples. It reveals that, for aerogel CRF1500-40, meso-porosity is dominant $(83.3 \%)$ in the carbon structure and the electro-active material has a meso-porous structure with a total pore volume, a meso-pore volume and an average pore diameter of $1.02 \mathrm{~cm}^{3} \mathrm{~g}^{-1}, 0.85 \mathrm{~cm}^{3} \mathrm{~g}^{-1}$ and $8.27 \mathrm{~nm}$, respectively. However, for aerogel CRF1000-30, though with very similar total pore volume, meso-pore volume and average pore size of $1.06 \mathrm{~cm}^{3} \mathrm{~g}^{-1}, 0.80 \mathrm{~cm}^{3}$ $\mathrm{g}^{-1}$ and $8.46 \mathrm{~nm}$ respectively, the meso-pores only appear around $16 \mathrm{~nm}$. Here, a synergy among specific surface area, pore volume and pore size distribution, which contributes to superior cycling performance, is confirmed by the later electrochemical test (see Fig. 2, Fig. 3 and Fig. 4).

Table 1. BET surface area, pore volume, pore diameter and conductivity data for 
carbon aerogels.

\begin{tabular}{lllllllll}
\hline Materials & $\begin{array}{l}\mathrm{S}_{\mathrm{BET}} \\
\left(\mathrm{m}^{2} \mathrm{~g}^{-1}\right)\end{array}$ & $\begin{array}{l}\mathrm{V}_{\text {total }} \\
\left(\mathrm{cm}^{3} \mathrm{~g}^{-1}\right)\end{array}$ & $\begin{array}{l}\mathrm{V}_{\text {micro }} \\
\left(\mathrm{cm}^{3} \mathrm{~g}^{-1}\right)\end{array}$ & $\begin{array}{l}\mathrm{V}_{\text {meso }} \\
\left(\mathrm{cm}^{3} \mathrm{~g}^{-1}\right)\end{array}$ & $\begin{array}{l}\mathrm{V}_{\text {meso }} \\
/ \mathrm{V}_{\text {total }}\end{array}$ & $\begin{array}{l}\mathrm{V}_{\text {micro }} \\
/ \mathrm{V}_{\text {total }}\end{array}$ & $\begin{array}{l}\mathrm{D}_{\text {BJH }} \\
(\mathrm{nm})\end{array}$ & $\begin{array}{l}\text { Conductivity } \\
\left(\mathrm{S} \mathrm{cm}^{-1}\right)\end{array}$ \\
\hline CRF1500-40 & 669.17 & 1.02 & 0.17 & 0.85 & $83.30 \%$ & $16.70 \%$ & $3.85,17.95$ & $12.18 \times 10^{-1}$ \\
\hline CRF1000-30 & 680.22 & 1.06 & 0.26 & 0.80 & $75.47 \%$ & $24.53 \%$ & 16.00 & $5.02 \times 10^{-1}$ \\
\hline
\end{tabular}

3.2. Electrochemical performance

3.2.1. Evaluation of the function of single pore and dual pore

The electrochemical performance of the carbon aerogel based electrode is examined by galvanostatic charge/discharge tests using a CT2001A battery tester. First, the mass accessibility of the dual pore structure and the common single pore structure is evaluated. As is shown in the Fig. 2, at a current density of $0.05 \mathrm{~mA} \mathrm{~cm}^{-2}$ and a fixed capacity of $0.1 \mathrm{mAh}$, the battery with dual pore aerogel coating cathode (CRF1500-40) runs 525 cycles comparing to 332 (reach $5.0 \mathrm{~V} ; 364$ cycles to $2.0 \mathrm{~V}$ ) cycles for that of the single pore aerogel cathode (CRF1000-30). And during the galvanostatic charge/discharge cycling, the voltage gaps for the CRF1500-40 and CRF1000-30 cathode are $0.89 \mathrm{~V}$ and $1.16 \mathrm{~V}$, respectively in the first cycle. We postulate that the difference can be ascribed to two reasons, one is the different electrical conductivity for the two different aerogels, $1.218 \mathrm{~S} \mathrm{~cm}^{-1}$ and $0.502 \mathrm{~S} \mathrm{~cm}^{-1}$ for CRF1500-40 and CRF1000-30 respectively, the other is the different pore structure. The two aerogels have very similar specific surface area, pore volume, meso-pore fraction and BJH pore size of $669.17 \mathrm{~m}^{2} \mathrm{~g}^{-1}, 680.22 \mathrm{~m}^{2} \mathrm{~g}^{-1}, 1.02 \mathrm{~cm}^{3} \mathrm{~g}^{-1}$, $1.06 \mathrm{~cm}^{3} \mathrm{~g}^{-1}, 83.30 \%, 75.47 \%, 17.95$ (and 3.85) $\mathrm{nm}$ and $16 \mathrm{~nm}$ respectively (see Table 1, Table S1). For CRF1500-40, it possesses two typical meso-pores, one 
concentrating at $3.85 \mathrm{~nm}$ and the other at $17.95 \mathrm{~nm}$, which can greatly diminish pore blockage and be convenient for mass transfer in two separate channels (see Fig. 4). Some pioneers in this area have referred that a meso-pore concentrating at $3.0 \sim 3.5 \mathrm{~nm}$ or $20 \sim 50 \mathrm{~nm}$ is beneficial for the battery cycling performance. $[19,22,56-58]$ The dual pore designed in our experimental may be just a desirable combination of these two pores. For aerogel CRF1000-30, pore only centers around $16 \mathrm{~nm}$. The two aerogels, with different pore structure and electrical conductivity, thus yield different ability for mass accessibility and cell performance. And conclusions can be arrived that dual pore might improve the mass accessibility and cell performance. Thus, all the later electrochemical experiments are carried out by using the dual pore CRF1500-40 as active coating materials except when the discharge rate capability is involved in (CRF1000-30 is also discussed for comparison). For aerogel CRF1000-30, after various galvanostatic charge/discharge cycling, the discharged/charged products are also proved to involve the reversible formation/decomposition of $\mathrm{Li}_{2} \mathrm{O}_{2}$ except for a little byproduct of $\mathrm{LiOH}$, with round-shaped granular precipitations (Fig. S4).
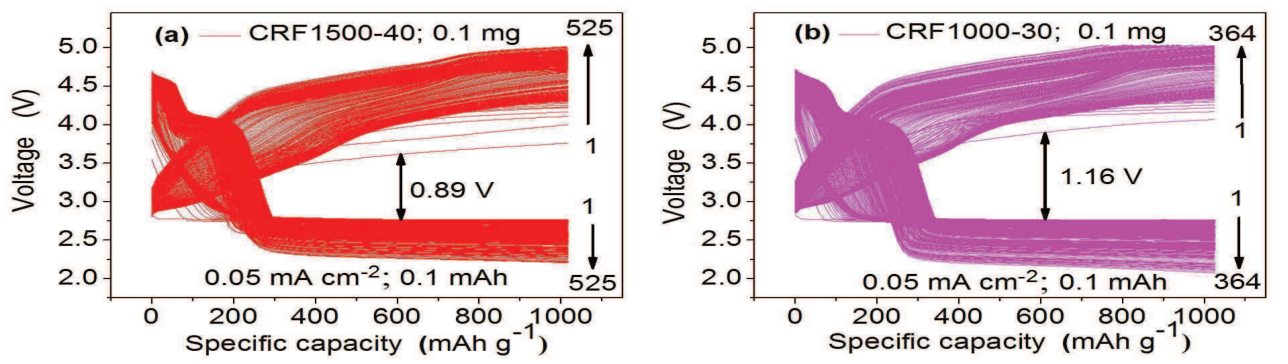

Fig. 2. Discharge-charge curves of the lithium-air batteries with (a) CRF1500-40 and (b) CRF1000-30 cathode at the same current density of different cycles in the oxygen environment. $1 \mathrm{M}$ LiTFSI/sulfolane is used as electrolyte; the current density and 
specific capacity are described as below: $0.05 \mathrm{~mA} \mathrm{~cm}^{-2}, 1000 \mathrm{mAh} \mathrm{g}^{-1}$. The cut off voltage scope is between $2.0 \mathrm{~V}$ and $5.0 \mathrm{~V}$ for discharge and charge, respectively.

\subsubsection{Carbon loading's affect on the cycling performance}

In order to find carbon loading's effect, we compare six cathodes with different carbon loading, ranging from $0.1 \mathrm{mg}$ to $0.6 \mathrm{mg}$, and discover that the cycling performance reduces as the carbon loading increases, but still keeps at least 78 cycles until the charging cutoff voltage reaches to $5.0 \mathrm{~V}$ for all the cases (see Fig. 3(a-b), Fig. S5 (a-f) and Table S2). Such prominent cycling stability may be associated with the carbon aerogel's inimitable dual pore, which could not be jammed simultaneously by discharged products of one kind of specific morphology, thus enhancing the reaction dynamics. We postulate that the inherent dual pore might inventively create a suitable tri-phase boundary reaction zone (see Fig. 4 (d)), facilitating oxygen and $\mathrm{Li}^{+}$diffusion in two independent pore channels. Furthermore, the large pore volume and high specific surface area can render more space for the deposition of discharged products and more active reactive sites and possibilities, respectively. All these potential advantages and characteristic lead to high energy efficiency above $65.18 \%$ and high final discharge voltage above $2.5 \mathrm{~V}$ of the initial 78 cycles for the batteries of all cases (see Fig. S6 and Fig. S7).
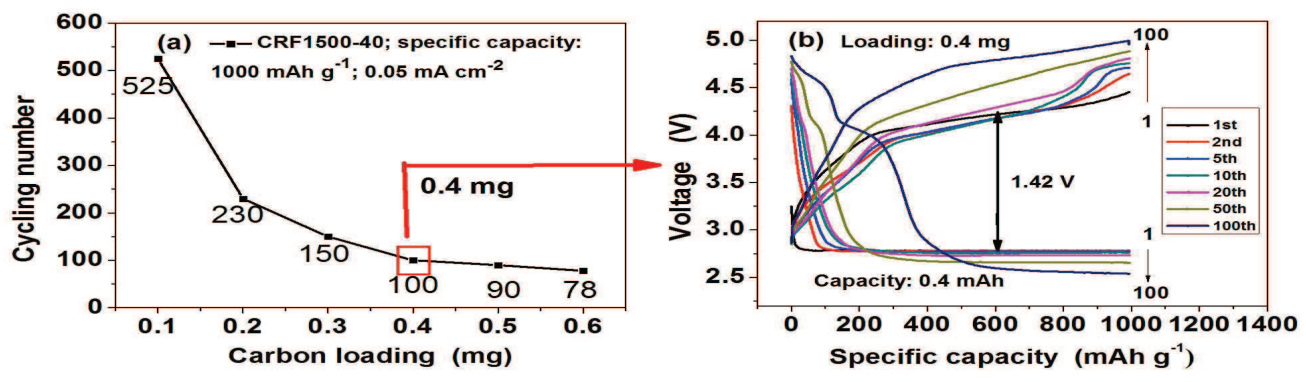
Fig. 3. Cycling life (a) and discharge-charge curves (b: $0.4 \mathrm{mg}$ ) of the lithium-air batteries with a CRF1500-40 carbon cathode of various loadings at different cycles. 1M LiTFSI/sulfolane is used as electrolyte; The current density is $0.05 \mathrm{~mA} \mathrm{~cm}^{-2}$ and specific capacity is $1000 \mathrm{mAh}^{-1}$. The carbon loading is ranging from $0.1 \mathrm{mg}$ to 0.6 mg.

For the cycling performance deterioration, it can be explained as below: the coating becomes thicker (or denser) and part of the pore volume is blocked along with the increasing carbon loading. The former leads to longer transportation path for $\mathrm{Li}^{+}$ and oxygen to travel to the active reaction sites, delaying the reaction kinetics. The later causes ineffective utilization of the total pore volume and intensifies the oxygen diffusion barrier. What's more, a great deal of precipitates that mainly consist of lithium peroxide form during discharge process, which is reported to be insoluble and insulated from granular to bulk morphology, scaling up the impedance of the whole battery (see Fig. 5, Fig. 6, Fig. 7, Fig. S8, Fig. S9 and Fig. S10). To remove the deposited products, higher charging voltage is needed, causing the voltage gap to become larger (1.42 V in the Fig. 3 compares to $0.89 \mathrm{~V}$ in the Fig. 2) and electrolyte to decompose.

After long time's accumulation, the lithium peroxide fills up the whole pore system to separate oxygen diffusion and deform the cathode (Large amount of precipitations will cause cathode expansion which leads to a non-intimate contact between carbon particles with the CP current collector; see Fig. 4(d)), and the electrolyte depletes, resulting in decreasing the discharge voltage to below $2.5 \mathrm{~V}$ and 
giving rise to the failure of the cell. To be highlighted, there are two to three voltage plateaus in the prolonged discharge or charge loading curves which are in directive of the probable side reactions. These parasitic reactions might involve the formation of $\mathrm{LiOH} \mathrm{H}_{2} \mathrm{O}$ (or $\mathrm{LiOH}$ ) and $\mathrm{Li}_{2} \mathrm{CO}_{3}$ besides $\mathrm{Li}_{2} \mathrm{O}_{2}$, which corresponds to the voltage of $4.3 \mathrm{~V}, 4.75 \mathrm{~V}$ and $3.75 \mathrm{~V}$, respectively, in the charging process and $4.2 \mathrm{~V}, 4.7 \mathrm{~V}$ and $2.5-2.75 \mathrm{~V}$ for that of the discharging state $[5,6,59-61]$.

3.2.3. Discharge depth and current density's affect on the cycling performance

In this section, the discharge/charge depth and current density's function on the cycling performance are investigated. Fig. 4(a) and Fig. S11(a-c) reveal that at a current density of $0.10 \mathrm{~mA} \mathrm{~cm}{ }^{-2}$, when the specific capacity is set to 1000,1500 and $2000 \mathrm{mAh} \mathrm{g}^{-1}$, the lithium-air batteries ran 112, 44 and 34 cycles, respectively, during the galvanostatic charge-discharge test. To construct a realistic applied battery, the test time was simultaneously prolonged to $2.3 \mathrm{~h}$ when the current density exceeded 0.10 $\mathrm{mA} \mathrm{cm}{ }^{-2}$. The battery cycling performance also reduces fast as the current density gets higher. Especially for a current density of $0.50 \mathrm{~mA} \mathrm{~cm}^{-2}$, less than 1 cycle (see Fig. 4(b), Fig. S11, Fig. S12) is obtained comparing to 33 cycles for the case of a relative low capacity $(0.4 \mathrm{mAh}$, Fig. S11(g)). Presumably the long time discharge process generates large amount of lithium peroxide which makes a blockage of pores, passivation of cathode (see Fig. 4(d)) and expansion of the air cathode, impeding oxygen diffusion, electron transfer and the gapless contact between the electrodes. Though the charge voltage reaches $5 \mathrm{~V}$ finally, the discharge voltage decreases apparently but still remains above $2.5 \mathrm{~V}$ in all the cases. 
Fig. 4(b) and Fig. S11(a, d-h) also show that the discharge voltage decreases as the current density elevates from 0.10 to $1.00 \mathrm{~mA} \mathrm{~cm}^{-2}$, but still keeps as high as 2.65 V similarly in the first cycle. Particular for a low current density of $0.02 \mathrm{~mA} \mathrm{~cm}^{-2}$, the battery obtains an ultra-high capacity of $14.8 \mathrm{mAh}$ (see Fig. S13). At a current density of $0.10,0.20,0.30,0.40$ and $0.50 \mathrm{~mA} \mathrm{~cm}^{-2}$, a superior cycling performance of 112,94 , 64,56 and 33 cycles is delivered. When the current density increases to $1.00 \mathrm{~mA} \mathrm{~cm}^{-2}$ or above (see Fig. 4(b), Fig. S11 and Table S5), there's no more than 18 cycles received. As we know, higher current density demands faster mass transportation (including $\mathrm{e}^{-}, \mathrm{O}_{2}$ and $\mathrm{Li}^{+}$) and electrochemical reaction in the batteries [24,25,59]. However, it takes times for electron, oxygen and $\mathrm{Li}^{+}$to diffuse to the tri-phase boundary reaction zone and react with each other to produce the lithium peroxide. Such slow transportation and reaction kinetics undoubtedly initiate reaction thirsty, undermining the whole batteries performance in high discharge rates. 

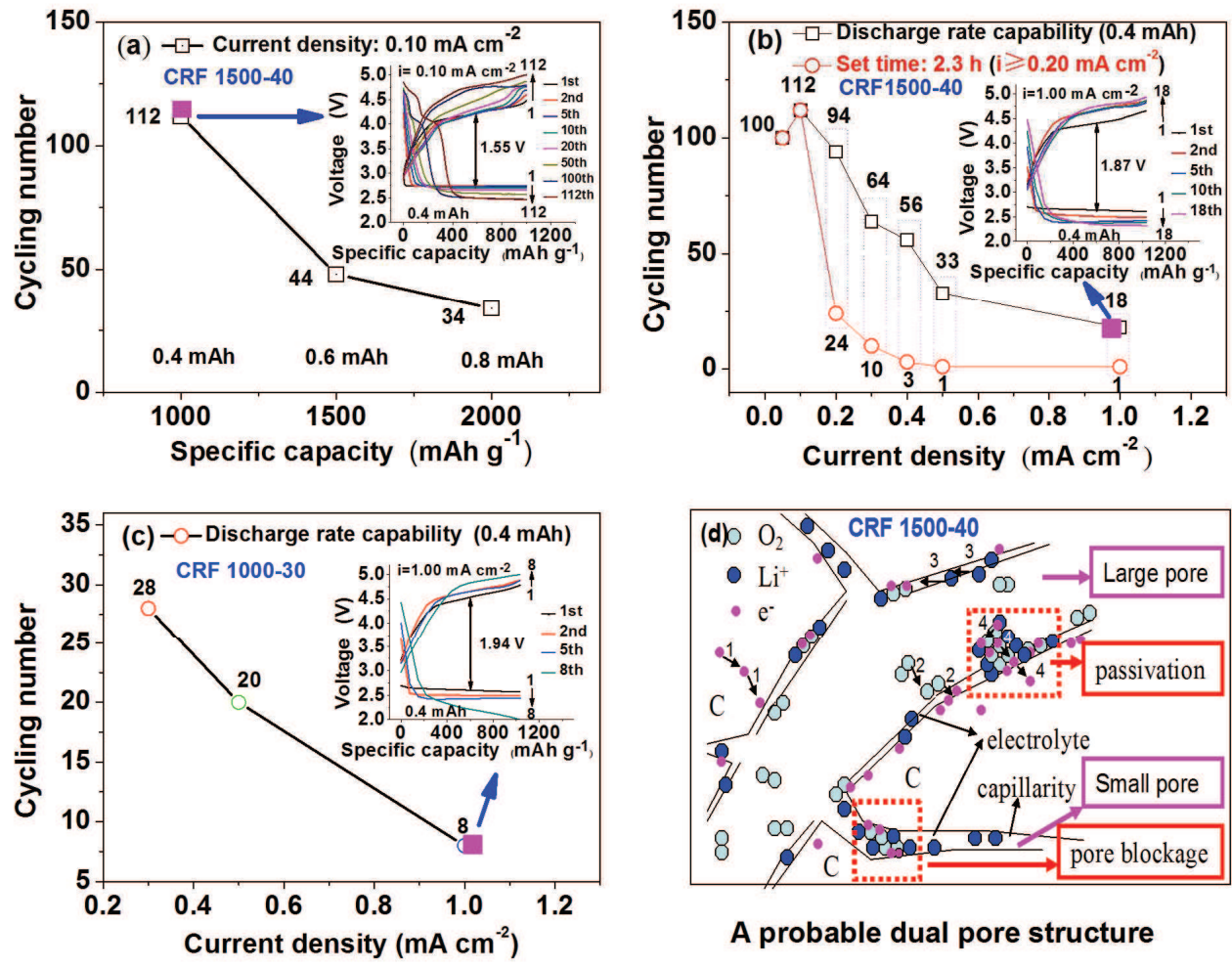

A probable dual pore structure

Fig. 4. Cycling life and its typical inset discharge-charge curves of the lithium-air batteries with a CRF1500-40 (Fig. 4 (a), Fig. 4 (b)) or CRF1000-30 (Fig. 4 (c)) carbon cathode at various discharge depth or current densities of different cycles, accompanied by an illustration of the proposed probable dual pore mechanism realizing the formation of a tri-phase boundary reaction zone (Fig. 4 (d)). 1 M LiTFSI/sulfolane is used as electrolyte and the carbon loading is $0.4 \mathrm{mg}$. The current density varies from $0.05 \mathrm{~mA} \mathrm{~cm}{ }^{-2}$ to $1.0 \mathrm{~mA} \mathrm{~cm}^{-2}$. The specific capacity is ranging from $1000 \mathrm{mAh} \mathrm{g}^{-1}$ to $10000 \mathrm{mAh} \mathrm{g}^{-1}$. The black line and red line in Fig. 4 (b) are on behalf of the specific capacity of $1000 \mathrm{mAh} \mathrm{g}^{-1}$ and the fixed time of $2.3 \mathrm{~h}$ (when current density $\geqslant 0.20 \mathrm{~mA} \mathrm{~cm}^{-2}$ ), respectively. Fig. 4 (d) also reveals several steps related with lithium peroxide formation/decomposition: 1). Electron transfers to catalytic active sites where oxygen is rich; 2). Oxygen diffuses through the electrolyte 
and accumulates on the catalytic active sites of aerogel surface; 3). Li ions migrates to the tri-phase reaction zone; 4). Electron travels through lithium peroxide layers to decompose lithium peroxides.

Nevertheless, it is not meant that the lower the better for the batteries when it comes to current density, which is deeply rooted in the basic results that the batteries exhibit better cycling performance $(0.4 \mathrm{mAh})$ at a current density of $0.10 \mathrm{~mA} \mathrm{~cm}{ }^{-2}$, comparing to that of $0.05 \mathrm{~mA} \mathrm{~cm}{ }^{-2}$, in addition to a realistic requirement of high power density. We postulate that such a discharge rate promotion might be traceable to the unique carbon structure of dual pore which facilitates the mass transport, thus resulting in a sufficient oxygen and $\mathrm{Li}^{+}$transport even in a relatively higher discharge rate and charge rate.

This is further verified by the cycling performance of single pore cathode CRF 1000-30 (Fig. 4(c)). At higher current densities of $0.3,0.5$ and $1.0 \mathrm{~mA} \mathrm{~cm}^{-2}$, cathodes with dual pore structure show 64,33 and 18 cycles comparing to 28,20 and 8 cycles for that of single pore, highlighting the superiority for mass transfer. In addition, the discharge voltage is higher and the charge voltage is lower in the first cycle for the dual pore CRF 1500-40 cathode in all cases, which is apparently shown in the Fig. 4(b), Fig. 4(c), Fig. S11 and Fig. S15. The general voltage gap of CRF 1500-40 is 1.87 V, lower than $1.94 \mathrm{~V}$ for that of CRF 1000-30. Such sufficient preponderance has a direct relation with CRF1500-40's higher electrical conductivity and better mass accessibility (dual pore). Considering that the electrical conductivity of the as-prepared six aerogel cathodes is very close and almost in the same level $(1 \mathrm{~S} / \mathrm{cm})$, 
if the electrical conductivity plays a major role, then why the aerogel CRF 1000-40 owns even superior pore parameter and higher electrical conductivity to CRF 1500-40 but exhibits poor cycling capability (see Fig. S1, Fig. S2, Table S1; Electrochemical performance data for CRF1000-40 are not shown here)? Thus, we postulate that the mass accessibility may be the key factor to determine the electrochemical performance of the lithium-air batteries. Besides, all these demonstrate that dual pore far exceeds single pore for mass transfer. Maybe, it's a favorable combination between the two types of effective meso-pores: $3 \sim 3.5 \mathrm{~nm}$ and $20 \sim 50 \mathrm{~nm}[19,22$, 56-58]. However, among the meso-pores, it needs further study to investigate whether the smaller pore $(3.85 \mathrm{~nm})$ or larger pore $(17.95 \mathrm{~nm})$ contributes more to the capacity.

Here, we postulate that the essence lies in that the distinctive dual pore carbon aerogel can successfully create a tri-phase boundary reaction zone (Fig. 4 (d)). The large pore is apt to facilitate oxygen penetration, and simultaneously yield and store discharged products at its abundant catalytically active carbon surface; while the small pore with little or non-catalytic active centre will be filled with highly conductive $\mathrm{Li}^{+}$ electrolyte due to the coalition of hydrophilic carbon surface and capillary pressure, conducive to $\mathrm{Li}^{+}$transfer. Charge is prone to travel through carbon aerogel's highly conductive interconnected 3D network, and accumulates at the high oxygen concentration sites. Li-oxide precipitations will be eventually filled in the pores where house a catalytic active junction (with an enormous amount of both $\mathrm{O}_{2}$ and $\mathrm{Li}^{+}$, complementary subsystems). In this way, common two-phase boundary reaction zone 
can be avoided, resulting in a higher discharge rate and reduced pore blockage. However, as is shown in Fig. 4(d), a long time discharge process or large capacity still initiates serious pore blockage or cathode passivation, thus the capacity should be limited to some degree. Maybe a fixed capacity of 1000 to $3000 \mathrm{mAh} \mathrm{g}^{-1}$ is reasonable and meaningful, which will be in the schedule of our future task.

At last, conclusion arrives that the favorable current density should be set ranging from 0.05 to $0.20 \mathrm{~mA} \mathrm{~cm}^{-2}$ when the cell works without a catalyst, which will contribute to excellent cycling performance. And the discharge depth should also be carefully controlled, maybe in a scope of 1000 to $3000 \mathrm{mAh} \mathrm{g}^{-1}$. It is worthwhile to note that most of the discharge or charge curves appear two to three potential plateaus which might be ascribed to the parasitic reaction of electrolyte or binder degradation, trace of water and carbon dioxide et al.. This hypothesis can be verified by the following XRD test (see Fig. 7, Fig. S4, Fig. S14), which detects the existence of $\mathrm{LiOH} \mathrm{H}_{2} \mathrm{O}$ (or $\mathrm{LiOH}$ ), $\mathrm{Li}_{2} \mathrm{CO}_{3}$ and other carbonate-based by-products besides $\mathrm{Li}_{2} \mathrm{O}_{2}$ $[5,6,59-61]$.

\subsubsection{Reversible electrochemical reaction and electrochemical impedance} spectroscopy analysis of the lithium-air batteries

The CV test is utilized to explore the lithium-air batteries' internal reversible redox reactions. Fig. 5(a) indicates that in the first cycle, a conspicuous oxidation peak and reduction peak appear at the voltage of $4.05 \mathrm{~V}$ and $2.30 \mathrm{~V}$, respectively. Current peak as high as $0.75-1.50 \mathrm{~mA}$ evinces that the carbon aerogel deposited onto CP exhibits exceptionally excellent electrochemical performance towards both 
formation and decomposition of discharged product, which might be derived from the high specific surface area, dual pore structure, large total pore volume and hydrophobic surface and so on. The second and third cycle performs a lower weak oxidation peak at $3.75 \mathrm{~V}$ and $3.87 \mathrm{~V}$, depicting an electro-activation process of the cell which makes the battery more stable [6,9]. For the subsequent two cycles, the oxidation and reduction peak maintain the same or analogous shape excluding a little potential migration to the high or low voltage correspondingly which demonstrates the relative stability of the cell reaction in spite of a little cathode polarization. It also signifies that sulfolane is a favorable electrolyte solvent for the lithium-air batteries.
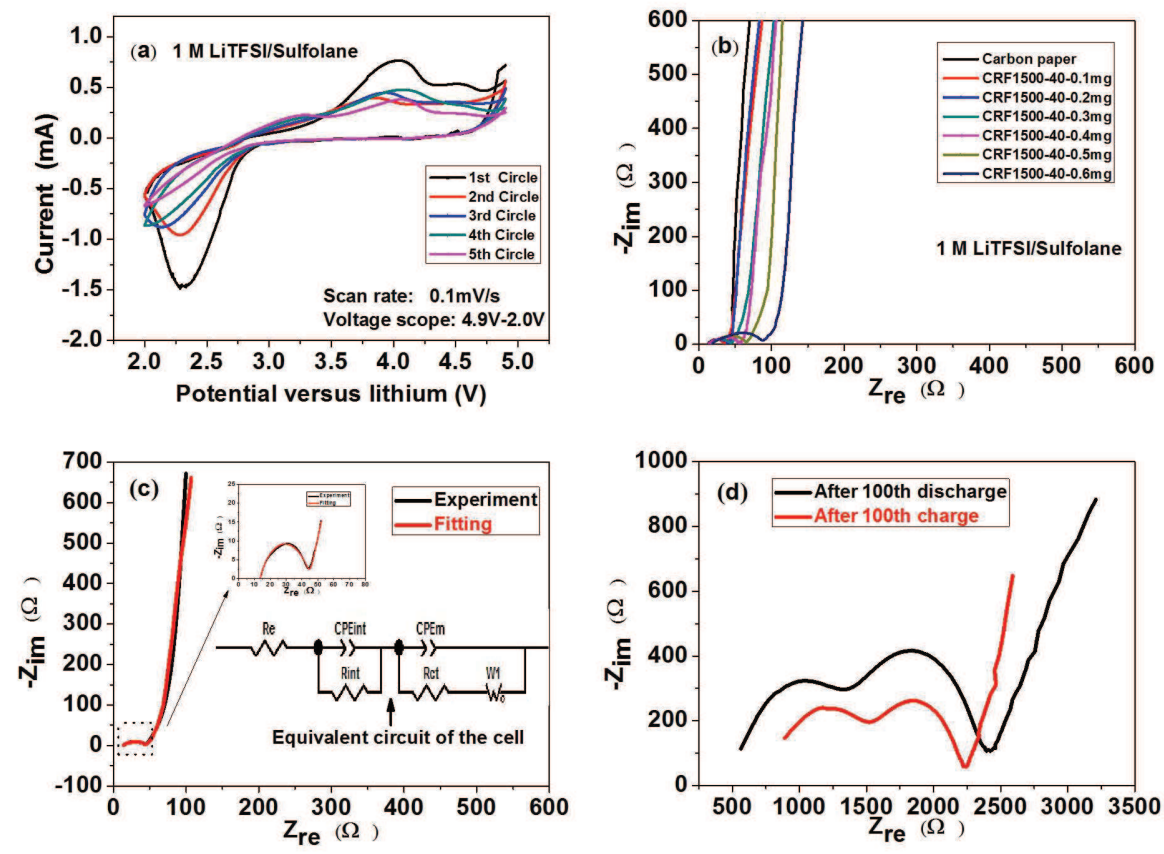

Fig. 5. CV curves and electrochemical impedance of lithium-air batteries at different cycles and the corresponding inset equivalent circuit. (a) The CV curve of the carbon aerogel electrode based lithium-air battery using a LiTFSI/sulfolane electrolyte. The $\mathrm{CV}$ results are carried out at a constant scan rate of $0.1 \mathrm{mV} \mathrm{s}^{-1}$ and the voltage scope is 
between $2.0 \mathrm{~V}$ and $4.9 \mathrm{~V}$; (b) Impedance spectra of the carbon paper substrate and fresh (pristine) carbon aerogel air cathode with different carbon loadings; (c) The experimental and fitting impedance of the above air cathode with a carbon loading of $0.4 \mathrm{mg}$ as well as the inset analog circuit of the cell; (d) The impedance of the lithium-air battery after 100th discharge and charge cycle for case Fig. 5(c).

Shown in Fig. 5(b-d) are the experimental and fitting impedance spectra, as well as the simulated circuit of the lithium-air batteries with various carbon loadings. The simulated circuit is consistent and similar with several articles previously reported [40,62-65]. With a gas diffusion electrode, the model should consider pore structure's influence on current density. Re represents the electrolyte resistance inside a porous electrode on basis of homogenous pore system, the bulk electrolyte ohmic resistance and the contacts with current collectors. CPE is constant phase element, and $\mathrm{C}_{\text {int }}$ is typical of surface films formed on the electrode. $\mathrm{R}_{\mathrm{ct}}$ is related to the charge transfer process at the catalyst surface while $\mathrm{C}_{\mathrm{m}}$ represents double-layer capacitance distributed between the ohmic and faradaic processes. $\mathrm{W}_{\mathrm{o}}$ is finite length Warburg resistance (open-circuit terminus), on behalf of kinetic resistance for oxygen and $\mathrm{Li}^{+}$, and affect the adsorption of oxygen on the catalytic active surface of the electrode.

Table S3 and Table S4 show the detailed data for the equivalent circuit and the fitting impedance spectra. The EIS test illustrates that the impedance increases with the addition of carbon loading which lowers the porosity of the air cathode and extends the diffusion path of the oxygen and $\mathrm{Li}^{+}$. What's more, it can be seen that the cell resistance grows larger as the discharge reaction proceeds and reduces 
accompanied with the corresponding charging process in most cases from the impedance test (see Fig. S8, Fig. S9 and Fig. S10). Although some impedance data is not so correlated with its carbon loading, the tendency is undoubtedly conformed, that is: cycle by cycle of galvanostatic charge-discharge test, the impedance gets larger and larger (Fig. 5(c, d), Fig. S8, Fig. S9 and Fig. S10). That can be attributed to the low conductivity and uncompleted decomposition of the discharged products, which will be clearly perceived from the SEM and XRD test in the next part (see Fig. 6 and Fig. 7).

Further more, two similar semicircles are observed in the impedance spectra, with a smaller one at high frequency and another larger one at low frequency. The low frequency semicircle exhibits larger changes as compared to that of the high frequency and there is little change for the high frequency intercept, implying that the deposition of the discharge products on the surfaces of carbon not only reduce the kinetics of oxygen reduction, but also affect the diffusion of dissolved oxygen on the electrolyte-catalyst (carbon) interface. It's highlighted that charge transfer resistance $\left(R_{c t}\right)$ occupies the main part of the three resistance distribution (see Fig. S9, Fig. S10, Table S3, Table S4) through various cycles which has direct connection with the accumulation of low electrical conductivity discharged products of $\mathrm{Li}_{2} \mathrm{O}_{2}$ in the cathode. Thus, cycle by cycle, cathode passivates seriously (see Fig. 4(d)) which leads the cell failure.

3.3. Electrochemical reaction process analysis and air's affect

3.3.1. Morphology and composition analysis of discharged/ charged products 
The morphology of discharged/charged products is recorded in Fig. 6, from which we can observe that granular precipitations to bulk or sheet-shaped depositions form in discharge and disappear in the subsequent charging process after 10th cycle. At low current density, granular precipitation inclines to be generated first for its easy nucleation and then gradually growing up to large separately flake-shaped species. However, for the high current density, mass limitation $\left(\mathrm{Li}^{+}\right.$and oxygen's sluggish transport to the active electrode surface) hinders the fast electrochemical reaction, yielding only considerable medium-sized granular to bulk depositions. In the conversed process, the formed products are vanished except some scattered depositions. With regard to deep discharge, the situation lies between slow discharge and fast discharge process, tending to form enormous granular to sheet-shaped aggregates which further deposit in the internal pore and drop the close contact between the electrodes. However, the large bulk-shaped depositions are not beneficial for superior cycling performance.

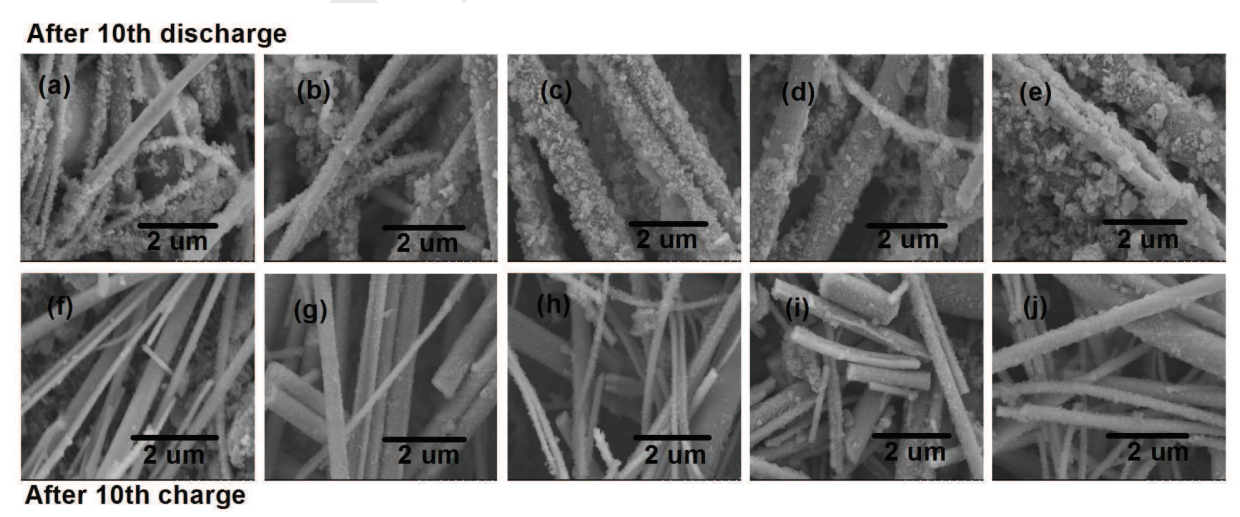

Fig. 6. Field emission scanning electron microscopic (FE-SEM) images of the discharged (above) and charged (below) CRF1500-40 cathode after 10 cycles. Current density and specific capacity are recorded as below: Fig. $6(\mathrm{a}, \mathrm{f}) 0.05 \mathrm{~mA} \mathrm{~cm}{ }^{-2}, 1000$ 
$\mathrm{mAh} \mathrm{g}^{-1} ; 6(\mathrm{~b}, \mathrm{~g}) 0.10 \mathrm{~mA} \mathrm{~cm}{ }^{-2}, 1000 \mathrm{mAh} \mathrm{g}^{-1} ; 6(\mathrm{c}, \mathrm{h}) 0.20 \mathrm{~mA} \mathrm{~cm}{ }^{-2}, 1000 \mathrm{mAh} \mathrm{g}^{-1}$; 6(d, i) $0.10 \mathrm{~mA} \mathrm{~cm}{ }^{-2}, 1500 \mathrm{mAh} \mathrm{g}^{-1}$; 6(e, j) $0.10 \mathrm{~mA} \mathrm{~cm}{ }^{-2}, 2000 \mathrm{mAh} \mathrm{g}^{-1}$. The rod-like materials comes from separator which adheres closely to the air cathode surface after electrochemical reaction.

The following XRD test (Fig. 7 and Fig. S14) confirms that the above-mentioned precipitations are dominantly $\mathrm{Li}_{2} \mathrm{O}_{2}$ combined with a little $\mathrm{LiOH} \mathrm{H}_{2} \mathrm{O}(\mathrm{LiOH})$ and $\mathrm{Li}_{2} \mathrm{CO}_{3}$, most of which are proved to be crystalline products in the all involved cases, regardless of the difference in the morphology of the discharge products. Especially, the discharged products show a fine crystalline at a low current density of $0.02 \mathrm{~mA}$ $\mathrm{cm}^{-2}$, indicating that low discharge rate favors to release lithium peroxide in crystal form (see Fig. S14), which is also in accordance with the large sheet-shaped deposits observed in Fig. 6. The formation of these byproducts may be related with: 1) the decomposition of $\mathrm{pVdF}$ to $\mathrm{H}_{2} \mathrm{O}_{2}$ and $\mathrm{HF}$, the former of which disproportionates to produce $\mathrm{H}_{2} \mathrm{O}$ first, then reacts with generated lithium peroxide; 2) the penetration of trace of water and carbon dioxide into the test environment after a prolonged time, which react with the yielding lithium peroxides; 3 ) the reaction that takes place at the cathode- $\mathrm{Li}_{2} \mathrm{O}_{2}$ interface $[5,60,66]$.

After the corresponding charging process (cutoff voltage: $4.75 \mathrm{~V}$ ), only a few relatively weak $\mathrm{Li}_{2} \mathrm{O}_{2}$ peaks but no other impurity peaks are detected, demonstrating that most of the previous formed lithium peroxides, lithium hydroxides and lithium carbonates are successfully decomposed. It also explains why the separator fiber still adheres intimately with small amount of granular or bulk particles in the above 
charged products (see Fig. 6). Based on this phenomenon, it is assumed that the high overcharge voltage is associated with the difficulty in decomposing the discharged products, especially for the complete removal of lithium carbonates under a high potential above $4.7 \mathrm{~V}$. Such high charge potential will inevitably initiate electrolyte decomposition, further accelerating the parasitic reactions which can be also discovered in the cycling performance test where several potential plateaus occur in the discharge or charge loading curves. With regard to qualitative or quantitative identification of all byproducts (particularly amorphous or low amount deposits), more advanced analysis techniques or equipment are needed, such as XPS, DEMS, FTIR, NMR, SERS et al., all of which are the task of our future research.
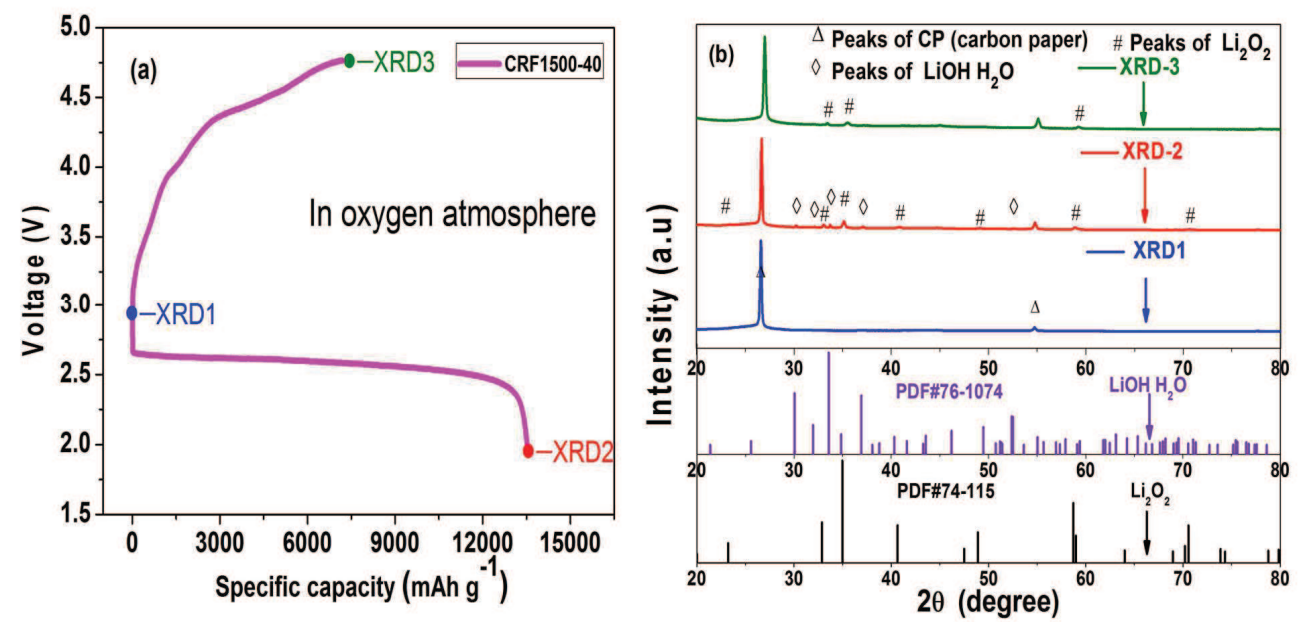

Fig. 7. Galvanostatic charge/discharge loading curve (a) and corresponding pristine, discharged and charged state XRD patterns for lithium-air batteries in the oxygen environment. The current density is $0.10 \mathrm{~mA} \mathrm{~cm}^{-2}$ and the voltage scope is between 2.0 $\mathrm{V}$ to $4.75 \mathrm{~V}$. The cathode carbon loading is $0.4 \mathrm{mg}$. The discharged products agree well with the PDF 74-115 of the crystalline lithium peroxide, and PDF76-1074 of the parasitic reaction products contain $\mathrm{LiOH} \mathrm{H}_{2} \mathrm{O}$, most of which disappear after the 
corresponding charging process.

3.3.2. Lithium-air batteries in air atmosphere

Finally, air's impact is also investigated. As is shown in Fig. 8, Fig. S16 and Table S6, when working in air atmosphere, the cycling number of the batteries decreases as the current density amplifies to $0.20 \mathrm{~mA} \mathrm{~cm}^{-2}$, though with a little promotion at $0.10 \mathrm{~mA} \mathrm{~cm}^{-2}$ which also fits most of the other cases $(40,48,8$ cycles correspond to current density of $0.05 \mathrm{~mA} \mathrm{~cm}^{-2}, 0.10 \mathrm{~mA} \mathrm{~cm}^{-2}$ and $0.20 \mathrm{~mA} \mathrm{~cm}^{-2}$ ). We postulate that such an improvement can be further ascribed to the peculiar cathode structure, which strengthens fast mass transport. What's more, in the ambient environment, the cycling performance of the lithium-air batteries never surpasses that of the previous oxygen circumstances (see Fig. S11, Fig. S12 and Fig. S16 (b, d)), for which trace of moisture and carbon dioxide, combined with the lower oxygen pressure might be blamed $[23,60,63]$. The cell voltage gap in air also exceeds that of the oxygen atmosphere, exhibiting of $2.16 \mathrm{~V}$ and $1.62 \mathrm{~V}$ respectively during the first cycle. The huge voltage gap might involve with some parasitic reactions.
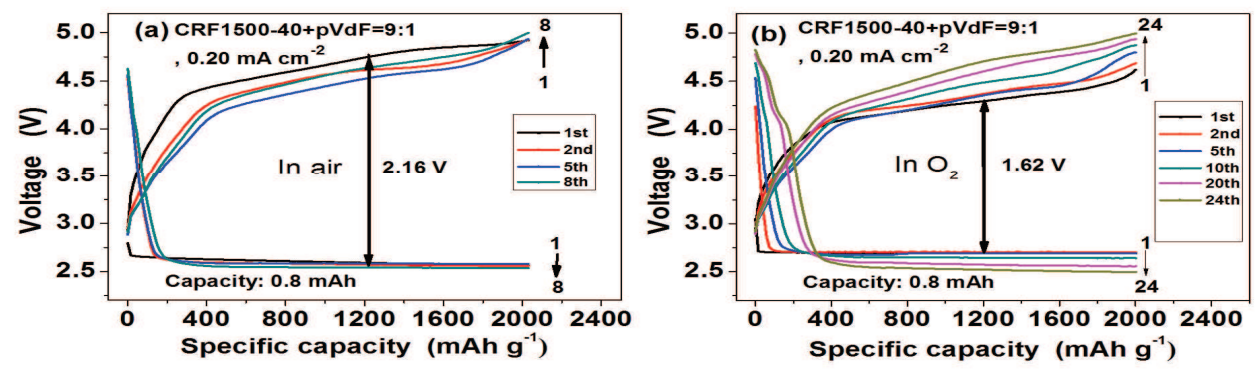

Fig. 8. Discharge-charge curves of the lithium-air batteries with CRF1500-40 cathode at various current densities of different cycles in the air environment (a) and oxygen environment (b). $1 \mathrm{M} \mathrm{LiTFSI/sulfolane} \mathrm{is} \mathrm{used} \mathrm{as} \mathrm{electrolyte.} \mathrm{The} \mathrm{current} \mathrm{density} \mathrm{is}$ 
$0.20 \mathrm{~mA} \mathrm{~cm}^{-2}$ and specific capacity is $2000 \mathrm{mAh} \mathrm{g}^{-1}$.

Under such circumstances, precipitations that form from discharge process might react with the impurities (water and carbon dioxide) to yield parasitic reaction products, such as $\mathrm{LiOH} \mathrm{H}_{2} \mathrm{O}, \mathrm{LiOH}$ and $\mathrm{Li}_{2} \mathrm{CO}_{3}$ as well as other lithium carboxyl carbonates, and vanish after corresponding charging process. These byproducts are further verified by the XRD analysis in Fig. 9(a, b). However, owing to low electrical conductivity and non-closely physical contact of the expansion of the air cathode (caused by cathode passivation, see Fig. 4(d)), they are difficult to be decomposed even under high voltage $(4.75 \mathrm{~V}$, see Fig. 7$)$, which might give rise to the side reactions of electrolyte degradation. It is not until the charging voltage reaches to 4.92 $\mathrm{V}$, all the characteristic peaks belonging to lithium peroxide, lithium hydroxide et al. disappear (see Fig. 7 and Fig. 9). As a result, to obtain high cycling performance in air atmosphere: (1) ambient air (oxygen) should be amply dry; (2) carbon dioxide should be completely removed; (3) the electrolyte, separator and all the electrode materials should also be thoroughly dried.
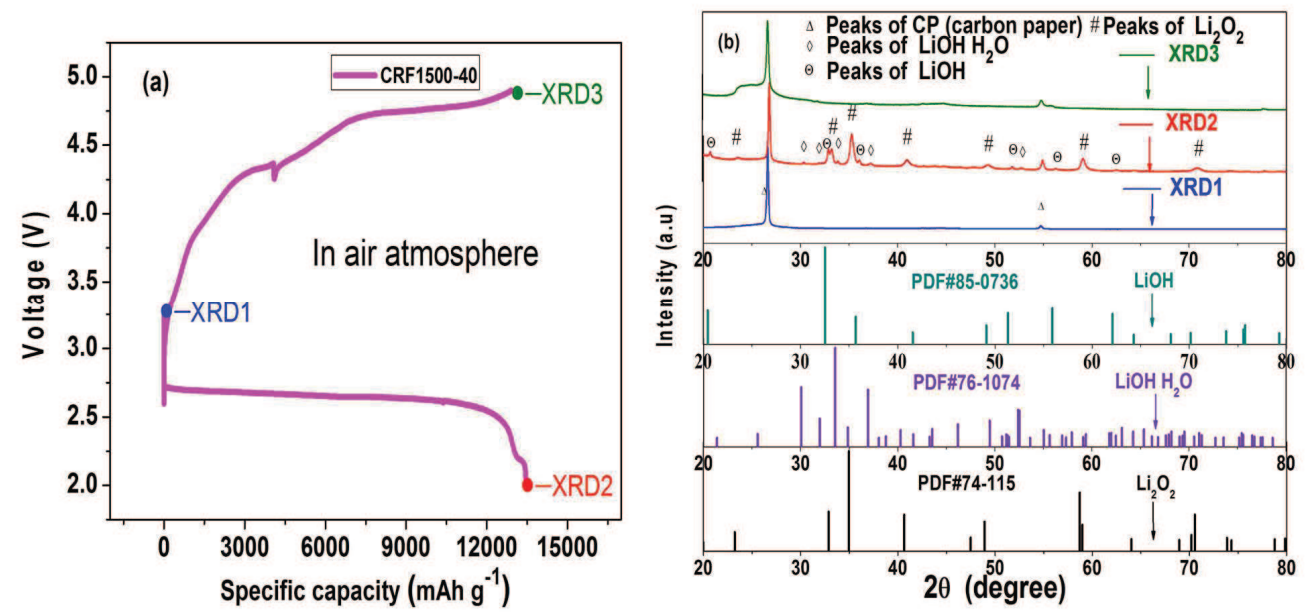
Fig. 9. Galvanostatic charge/discharge loading curve (a) and corresponding pristine, discharged and charged state XRD patterns for lithium-air batteries in the air environment. The current density is $0.10 \mathrm{~mA} \mathrm{~cm}^{-2}$ and the voltage scope is between 2.0 $\mathrm{V}$ to $4.92 \mathrm{~V}$. The cathode carbon loading is $0.4 \mathrm{mg}$. The discharged products agree well with the PDF 74-115 of the crystalline lithium peroxide, and PDF76-1074, PDF85-0736 of the parasitic reaction products for $\mathrm{LiOH} \mathrm{H}_{2} \mathrm{O}$ and $\mathrm{LiOH}$, respectively, most of which disappear after the corresponding charging process.

\section{Conclusions}

In summary, a well-modified air cathode with carbon aerogel deposited onto carbon paper was synthesized to obtain an excellent cycling performance (525 to 18 cycles at a current density ranging from 1.00 to $0.05 \mathrm{~mA} \mathrm{~cm}^{-2}$ ). The dual pore carbon structure and large pore volume, combined with superior conductivity are all favorable for the fast mass transport and superior discharged products accommodation and decomposition. We postulate that such a novel nano-porous cathode structure inventively create a suitable tri-phase boundary reaction zone, facilitating oxygen and $\mathrm{Li}^{+}$diffusion in two independant pore channels, thus realizing a relatively higher discharge rate cycling performance and lower pore blockage and cathode passivation. Hence, it is expected to promote the practical applications of lithium-air batteries by improving their recycling possibility with the help of relatively stable electrolyte, dry oxygen environment, feasible current density and discharge depth. Sulfolane is confirmed to be relatively stable according to our work (demonstrated by CV test and high cycle life), but its detailed changes particularly under high charge voltage still 
needs a further study by the DEMS, FTIR and XPS analysis (to identify the reaction deposits of amorphous state or low amount). Further more, after carefully controlling the current density and depth of discharge (DOD), and in an oxygen-filled environment which has high oxygen partial pressure and low amount of water and carbon dioxide, the lithium-air batteries can successfully run 112 and 94 cycles at a specific capacity of $1000 \mathrm{mAh} \mathrm{g}^{-1}$ and current density of 0.10 and $0.20 \mathrm{~mA} \mathrm{~cm}^{-2}$, respectively.

However, the cycling number reduces fast as the current density increases to 1.00 $\mathrm{mA} \mathrm{cm}{ }^{-2}$ or above, which may be related with the slow transport of $\mathrm{e}^{-}, \mathrm{Li}^{+}$and oxygen, causing limited reaction kinetics. Therefore, much work is still needed to resolve these problems. Herein, we propose a cation modified air electrode by adding the carbon with the $\mathrm{Li}^{+}$or other complexing-cations containing electrolyte in the process of fabricating nano-porous air cathode. In this way, $\mathrm{Li}^{+}$exists in the air cathode which greatly shortens the transportation path, favoring the high current density discharge/charge reaction. The complexing-cations improve the solubility of alkaline peroxides $[26,65]$. Meanwhile, little or no electrolyte would be added to the side of separator which faces to the cathode, minimizing blockage by electrolyte which traditionally fills in the meso-pores of the cathode.

\section{Acknowledgements}

This work was supported by Shenzhen Key Laboratory of New Lithium-Ion Battery and Mesoporous Materials, and Shenzhen Science and Technology Fund (JCYJ20130329102936684 and CXZZ20120615155541404). We thank Zheng-Wang 
Lu, and College of Material Science and Engineering (SZU) for helpful chemical analysis and instruments support, respectively.

\section{References}

[1] G. Girishkumar, B. McCloskey, A.C. Luntz, S. Swanson, W. Wilcke, J. Phys. Chem. Lett 1 (2010) 2193-2203.

[2] J. Christensen, P. Albertus, R.S. Sanchez-Carrera, T. Lohmann, B. Kozinsky, R. Liedtke, J. Ahmed, A. Kojica, J. Electrochem. Soc. 159 (2012) R1-R30.

[3] P.G. Bruce, S.A. Freunberger, L.J. Hardwick, J.-M. Tarascon, Nat. Mater 12 (2012) 19-29.

[4] R. Younesi, Acta Universitatis Upsaliensis. Digital Comprehensive Summaries of Uppsala Dissertations from the Faculty of Science and Technology 1001. 65 pp. Uppsala. ISBN 978-91-554-8544-3, 2012.

[5] T. Zhang, H.S. Zhou, Nat. Commun. 4 (2013) 1817-1823.

[6] B. Sun, P. Munroe \& G.X. Wang, Sci. Rep. 3 (2013) 2247-2253.

[7] Z.Q. Peng, S.A. Freunberger, Y.H. Chen, P.G. Bruce, Science 337 (2012) $563-566$.

[8] M.M.O. Thotiyl, S.A. Freunberger, Z.Q. Peng, Y.H. Chen, Z. Liu, P.G. Bruce, Nat. Mater. 12 (2013) 1050-1056.

[9] H.-G. Jung, J. Hassoun, J.-B. Park Y.-K. Sun, B. Scrosati, Nat. Chem. 4 (2012) $579-585$.

[10] Y.H. Chen, S. A. Freunberger, Z.Q. Peng, O. Fontaine, P. G. Bruce, Nat. Chem. 5 (2013) 489-494. 
[11] L.X. Wang, M. Ara, K. Wadumesthrige, S. Salley, K.Y. Simon Ng, J. Power Sources 234 (2013) 8-15.

[12] J.-J. Xu, D. Xu, Z.-L. Wang, H.-G. Wang, L.-L. Zhang, X.-B. Zhang, Angew. Chem. Int. Ed. 52 (2013) 3887-3890.

[13] J.J Xu, Z.-L. Wang, D. Xu, L.-L. Zhang, X.-B. Zhang, Nat. Commun. 4 (2013) $2438-2437$.

[14] H.-D. Lim, H. Song, H. Gwon, K.-Y. Park, J. Kim, Y. Bae, H. Kim, S.-K. Jung, T. Kim, Y. H. Kim, X. Lepró, R. O.-Robles, R. H. Baughman, K. Kang, Energy Environ. Sci. 6 (2013) 3570-3575.

[15] H.-D. Lim, H. Song, J. Kim, H. Gwon, Y. Bae, K.-Y. Park, J.Hong, H. Kim, T. Kim, Y. H. Kim, X. Lepr, R. O.-Robles, R. H. Baughman, K. Kang Angew. Chem. Int. Ed. 53 (2014) 3926-3931.

[16] T. Kuboki., T. Okuyama, T. Ohsaki, N. Takami, J. Power Sources 146 (2005) 766-769.

[17] X.H Yang, P. He, Y.-Y. Xia, Electrochem. Commun. 11 (2009) 1127-1130.

[18] S.R. Younesi, S. Urbonaite, F. Björefors, K. Edström, J. Power Sources 196 (2011) 9835-9538.

[19] Y.L. Li, X.F. Li, D.S. Geng, Y.J. Tang, R.Y Li, Carbon 64 (2013) 170-177.

[20] D.Y. Zhai, H. H. Wang, J.B. Yang, K. C. Lau, K. Li, K. Amine, L. A. Curtiss, J. Am. Chem. Soc. 135 (2013) 15364-15372. 
[21] D. M. Itkis, D. A. Semenenko, E. Y. Kataev, A. I. Belova, V. S. Neudachina, A. P. Sirotina, M.Hävecker, D. Teschner, A. K.-Gericke, P Dudin,A. Barinov, E. A. Goodilin, Y. Shao-Horn, L. V. Yashina, Nano Lett. 13(2013) 4697-4701.

[22] J. Xiao, D.H. Wang, W. Xu, D.Y Wang, R. E. Williford, J. Liu, J.-G. Zhang, J Electrochem. Soc. 157 (2010) A487-A492.

[23]Y.N. Zhang, H.M. Zhang, J. Li, M.R. Wang, H.J. Nie, F.X. Zhang, J. Power Sources 240 (2013) 390-396.

[24] M. Balaish, A. Kraytsberg, Y. Ein-Eli, ChemElectroChem 1 (2014) 90-94.

[25] M. Balaish, A. Kraytsberg and Y. Ein-Eli, Phys. Chem. Chem. Phys. 16 (2014) $2801-2822$.

[26] C.M. Li, O. Fontaine, S. A. Freunberger, L. Johnson, S. Grugeon, S. Laruelle, P. G. Bruce, M. Armand, J. Phys. Chem. C. 118 (2014) 3393-3401.

[27] R.E. Williford, J.-G. Zhang, J. Power Sources 194 (2009) 1164-1170.

[28] J. Xiao, D.H. Mei, X.L. Li, W. Xu, D.Y. Wang, G. L. Graff, W. D. Bennett, Z.M. Nie, L. V. Saraf, I. A. Aksay, J. Liu, J.-G. Zhang, Nano Lett. 11 (2011) $5071-5078$.

[29]Y. Matsuda, M. Morita, K. Yamada, K. Hirai, J. Electrochem. Soc. 132 (1985) $2538-2543$.

[30] D. Xu, Z.-L.Wang, J.-J Xu, L.-L. Zhang, L.-M. Wang, X.-B. Zhang, Chem. Commun. 48 (2012) 11674-11676.

[31] M. Sedlarikova1, J. Vondrak1, J. Maca1, K. Bartusek, J. New Mat. Electrochem. Systems 16 (2013) 065-071. 
[32] F. Wang, C.-S. Liang, D.-L. Xu, H.-Q. Cao, H.-Y. Sun, Z.-K. Luo, J. Inorg. Mater. 27 (2012) 1233-1242.

[33] C.S. Liang, F. Wang, Y.H. Xu, J. Chen, D. Liu, Z.K. Luo, New J. Chem. 37 (2013) 2568-2571.

[34] F. Wang, C.-S. Liang, Y. Pang, Y.-H. Xu, Z.-K. Luo. Ionics. 19 (2013) $1791-1793$.

[35] Z.-K. Luo, C.-S. Liang, F. Wang,Y.-H. Xu,J. Chen, D. Liu, H.-Y. Sun, H. Yang, X.-P. Fan, Adv. Funct. Mater. 24 (2014) 2101-2105.

[36] M. Balaisha, A. Kraytsbergb, Y. Ein-Eli, Phys. Chem. Chem. Phys. 16 (2014) $2801-2822$.

[37] R. W.Pekala, P. Hill, Calif. US Patent 4873218, 1989.

[38] M. Mirzaeian,P. J. Hall, Power System Technology 31 (2007) 90-96.

[39] M. Mirzaeian, P. J. Hall, Electrochimica Acta. 54 (2009) 7444-7453.

[40] M. Mirzaeian, P. J. Hall, J. Power Sources 195 (2010) 6817-6824.

[41] S.K. Das, S.M. Xu, A.-H. Emwas, Y.Y. Lu, S. Srivastava, L. A. Archer, Energy Environ. Sci. 5 (2012) 8927-8931.

[42] M. Mirzaeian, P. J. Hall, F. B. Sillars, I. Fletcher, M. M. Goldin, G. O. Shitta-bey and H. F. Jirandehie, J. Electrochem. Soc. 160 (2013) A25-A30.

[43] S.B. Ma, D. J. Lee, V. Roev, D. Im, S.-G. Doo, J. Power Sources 244 (2013) 494-498.

[44] B.D. McCloskey, D.S. Bethune, R.M. Shelby, G. Girishkumar, A.C. Luntz, J. Phys. Chem. Lett. 2 (2011) 1161-1166. 
[45] V.S. Bryantsev, V. Giordani, W. Walker, M. Blanco, S. Zecevic, K. Sasaki, J. Uddin, D. Addison, G.V. Chase, J. Phys. Chem. A 115 (2011) 12399-12409.

[46] S.A. Freunberger, Y.H. Chen, Z.Q Peng, J.M. Griffin, L.J. Hardwick, F. Barde, Petr Novak, P. G. Bruce, J. Am. Chem. Soc. 133 (2011) 8040-8047.

[47] Y.H. Chen, S. A. Freunberger, Z.Q. Peng, F. Barde, P.G. Bruce, J. Am. Chem. Soc. 134 (2012) 7952-7957.

[48] J.L Shui, J. Okasinskib, D. Zhao, J. Almerb, D.J. Liu, ECS Trans. 50 (2012) $37-45$.

[49] F.J. Li, T. Zhang, H.S. Zhou, Energy Environ. Sci. 6 (2013) 1125-1141.

[50] M.D. Radin, J.F. Rodriguez, F. Tian, D.J. Siegel, J. Am. Chem.Soc. 134 (2012) 1093-1103.

[51] S. P. Ong, Y.F. Mo, G. Ceder, Phys. Rev. B 85 (2012) 081105 (R).

[52] R.R. Mitchell, B.M. Gallant, Y. Shao-Horn, C.V. Thompson, J. Phys. Chem. Lett. 4 (2013) 1060-1064.

[53] B.D. Adams, C. Radtke, R. Black, M. Trudeau, K. Zaghib, L.F. Nazara, Energy Environ. Sci. 6 (2013) 1772-1794.

[54] M.D. Radin, D.J. Siegel, Energy Environ. Sci. 6 (2013) 2370-2379.

[55] B.M. Gallant, D.G. Kwabi, R.R. Mitchell, J.G Zhou, C.V. Thompson, Y. Shao-Horn, Energy Environ. Sci. 6 (2013) 2518-2528.

[56] C. Tran, X.-Q. Yang, D. Qu, J. Power Sources 195 (2010) 2057-2063.

[57] X. Ren, S. S. Zhang, Dat T. Tran, J. Read, J. Mater. Chem. 21 (2011) $10118-10125$. 
[58] L.-L. Zhang, Z.-L. Wang, D. Xu, X.-B. Zhang, L.-M. Wang, International J. Smart and Nano Materials 4 (2013) 27-46.

[59] E. Nasybulin, W. Xu, M.H. Engelhard, Z.M. Nie, S.D. Burton, L. Cosimbescu, M.E. Gross, J.-G. Zhang, J. Phys. Chem. C 117 (2013) 2635-2645.

[60] R. Black, S.H. Oh, J.-H. Lee, T. Yim, B. Adams, L.F. Nazar, J. Am. Chem. Soc. 134 (2012) 2902-2905.

[61] Y.C. Lu, Y. Shao-Horn, J. Phys. Chem. Lett. 4 (2013) 93-99.

[62] H. Kitaura, H. Zhou, Adv. Energy Mater. 2 (2012) 889-894.

[63] X.-H. Yang, Y.-Y. Xia, J. Solid State Electrochem. 14 (2010) 109-114.

[64] D. Zhang, Z. Fu, Z. Wei, T. Huang, A. Yu., J. Electrochem. Soc. 157 (2010) A362-A365.

[65] J. Adams, M. Karulkar, V. Anandan, J. Power Sources 239 (2013) 132-143.

[66] Y.L. Liu, R. Wang, Y.C. Lyu, H. Li, L.Q. Chen, Energy Environ. Sci. 7 (2014) $677-681$. 


\section{Supporting Information:}

\section{A dual pore carbon aerogel based air cathode for a highly rechargeable lithium-air battery}

Fang Wang a, *, Yang-Hai Xu ${ }^{\text {a }}$, Zhong-Kuan Luo a, b,*, Yan Pang a , Chun-Sheng Liang a , Jing Chen ${ }^{\mathrm{a}}$ and Dong Liu ${ }^{\mathrm{a}}$, Xiang-hua Zhang a,c

${ }^{a}$ College of Chemistry and Chemical Engineering, Shenzhen University, 3688 Nanhai Avenue, Nanshan District, Shenzhen 518060, China. Fax: +86 755 26536141; Tel: +86 755 26558125; E-mail: wangfsz@szu.edu.cn

${ }^{b}$ Zhejiang California International NanoSystems Institute \& Department of Materials Science and Engineering, Zhejiang University, 38\# Zhe Da Road, Hangzhou 310000, China. Tel: +86755 26557249; Fax: +86 755 26536141; E-mail:lzk@szu.edu.cn 'Laboratory of glasses and Ceramics, UMR CNRS 6226 "Institut des Sciences Chimiques de Rennes", Université de Rennes I, 35042 Rennes, France. Fax: +33 23235611; Tel: +33 2 23236937;E-mail:xzhang@univ-rennes1.fr

This Supporting Information contains Experimental methods, results and discussion of 16 supplementary figures comprising 57 panels in total with brief legends and 6 supplementary tables.

\section{Experimental methods}

\subsection{Synthesis and characterization of carbon aerogel}

\section{Synthesis of carbon aerogel}

Carbon aerogel has been traditionally synthesized through various processes including sol-gel reaction, acetic acid treatment, solvent exchange, supercritical drying and carbonization under inert atmosphere. In this article, resorcinol $(\mathrm{R})$ and formaldehyde $(\mathrm{F})$ were chosen as reaction precursor. Sodium carbonate (C) and deionized water were used as catalyst and solvent, respectively. The molar ratio of $\mathrm{R} / \mathrm{C}$ and $\mathrm{R} / \mathrm{F}$ were controlled to 1000:1-2000:1, 1:2 respectively. The reactant mass fraction was $40 \%$ (or 30\%). The mixture was first stirred vigorously into a homogeneous solution, and then cured at $353 \mathrm{~K}$ for three days in a sealed container, followed by one day trifluoroacetic acid treatment to further strengthen the gel configuration net. After that, fresh acetone was utilized to immerse the 
wet gels three times (one time a day) to replace water in the holes which was helpful to avoid net structure collapse. By this step, RF aerogel (ie, RF1500-40) was obtained. Finally, the wet gels were pyrolyzed in a tubular furnace under Ar atmosphere at $1323 \mathrm{~K}$ for 4 hours, yielding carbon aerogel (CRF1500-40). Other carbon aerogels, such as CRF1000-30 et al., were obtained simultaneously.

\section{Materials characterization}

The morphology and particle size of the RF aerogels and carbon aerogels were characterized by FE-SEM using the Hitachi SU-70 Thermal Field Emission Scanning Electron Microscope by operating at $2.0 \mathrm{KV}$ and TEM using the PHILIPS TECNAI-10 with an accelerating voltage ranging of 40-120 KV. The TG-DTA test was employed to determine the carbonization temperature and following degas temperature using a STA409PC Sync thermal analyzer (Germany Netzsch Instruments Manufacturing Co., Ltd.), which was performed using $10 \mathrm{mg} \mathrm{RF}$ aerogel and a heating rate of $10 \mathrm{~K} \mathrm{~min}{ }^{-1}$, from ambient temperature to $1673 \mathrm{~K}$ under $\mathrm{N}_{2}$ atmosphere. The BET surface area, porosity and pore size distribution of the sample were inspected by the analysis of static low temperature nitrogen adsorptiondesorption measurement with a NOVA1200e adsorption analyzer (Micromeritics) at $77 \mathrm{~K}$. The carbon aerogel powder was degassed at $573 \mathrm{~K}$ for $4 \mathrm{~h}$ prior to analysis.

\subsection{Preparation and characterization of carbon cathode}

\section{Preparation of carbon cathode}

A mixture of carbon aerogel and $\mathrm{pVdF}$ powder (with a weigh ratio of 9:1) was grinded for half an hour using mortar/pestle and was gathered in a weighing bottle. Several drops of NMP solution were added into the above mixture, stirring for $6 \mathrm{~h}$ more in order to get appropriate viscosity slurry. The asprepared suspension was used to coat carbon fiber paper substrate (HCP120 fuel cell carbon fiber paper; size: $100 \mathrm{~mm} \times 70 \mathrm{~mm} \times 0.21 \mathrm{~mm}$; purchased from Shanghai hesen Electric Co., Ltd. ) with the coating thickness of $100 \mu \mathrm{m}$. After drying in vacuum at $80{ }^{\circ} \mathrm{C}$ for another $6 \mathrm{~h}$, the above coated substrate was punched into round shape pellet (size: $\Phi 15 \mathrm{~mm} \times(0.21 \pm 0.15 \mathrm{~mm})$ ). At last, various carbon cathode electrodes, with carbon loading varying from $0.1 \mathrm{mg}$ to $0.6 \mathrm{mg}$ unequally, were 
obtained. The aerogel loading also can be shown in the unit of $\mathrm{mg} \mathrm{cm}^{-2}$, that is in the range of 0.057 $\mathrm{mg} \mathrm{cm} \mathrm{cm}^{-2}-0.340 \mathrm{mg} \mathrm{cm}^{-2}$.

\section{Cathode characterization}

The electrical conductivity of the air electrode and carbon aerogel was measured using the standard electrical four-probe method by a RTS-9 twin four-probe electrical measuring instrument (purchased from Guangzhou four probe tech. Co., Ltd.).

\subsection{Cell assembling and testing}

\section{Assembling the cell}

In this article, the coin cell (CR2032; all the related kits and assembling tools were purchased from MTI Shenzhen Corp.) was assembled in an argon-filled glove box (MBraun) with moisture and oxygen concentration lower than $0.5 \mathrm{ppm}$. The lithium air battery, in fact a laminated configuration like a sandwich (Li anode/separator/cathode, see Fig. S1.), was fabricated as below. The stainless steel spring was put at the bottom of the cell (Anode cap) first, on top of which was the gasket (stainless steel spacer). Then a lithium disk (Size: $\Phi 15 \mathrm{~mm} \times 0.5 \mathrm{~mm}$; Bought from China Energy Lithium Co., Ltd. ) , the separator (whatman GF/D glass microfiber filter paper; Size: $\Phi 17 \mathrm{~mm} \times 1 \mathrm{~mm}$; Bought from Beijing Jingkehongda Biotechnology Co., Ltd) dipped in the $1 \mathrm{M}$ LiTFSI/sulfolane electrolyte (Battery grade; purchased from Shenzhen Capchem technology Co., Ltd. ) and the carbon electrode fabricated previously (with the coating side facing to the separator) were placed successively on the gasket. Since the carbon fiber paper had high conductivity of $150 \mathrm{~S} / \mathrm{cm}$ and perfect hydrophobility on the opposite side of the coating, the collector and hydrophobic gas permeable membrane were saved. Finally, the positive electrode cap, containing a number of holes $(\Phi=1 \mathrm{~mm})$ which were convenient for oxygen traveling, was covered the cell bottom and sealed under $40 \mathrm{MPa}$. Then, it aged for more than $12 \mathrm{~h}$ in the glove box. 


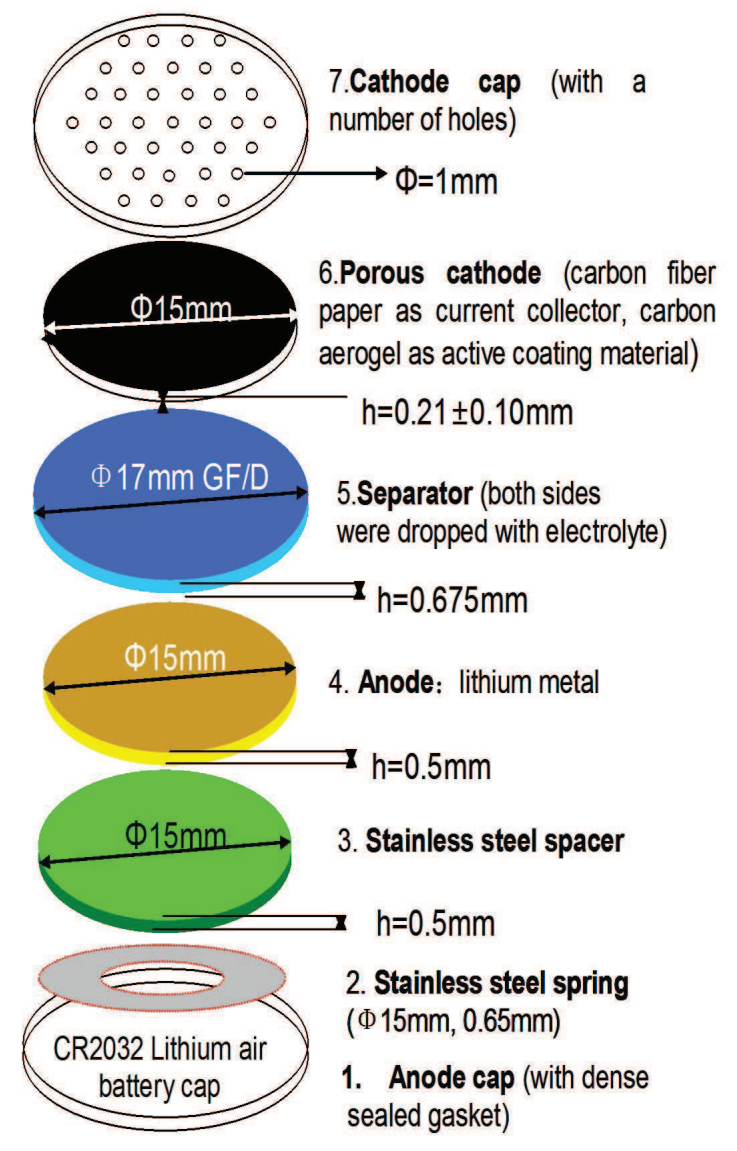

Fig. S1. The schematic diagram of the lithium-air battery model (CR2032).

\section{Cell testing and discharge/charge product characterization}

The cell was then exposed to $\mathrm{O}_{2}$ atmosphere $(1 \mathrm{~atm})$ for a minimum of 30 min prior to the electrochemical tests. Here, a minimum of 30 minutes exposing to the oxygen had been verified best by our previous experimental which contained series of exposure time. Among all the exposing time of $5 \mathrm{~min}, 15 \mathrm{~min}, 30 \mathrm{~min}, 45 \mathrm{~min}, 60 \mathrm{~min}, 2 \mathrm{~h}, 3 \mathrm{~h}$ and $4 \mathrm{~h}$, cells exposed to oxygen with $30 \mathrm{~min}$ to $1 \mathrm{~h}$ exhibit the best cycling performance. When the exposure time is more than $1 \mathrm{~h}$, no significant improvement of cycling performance has been achieved. Therefore, we choose an exposing time of more than $30 \mathrm{~min}$ as our experimental boundaries as well as for a short testing period. Galvanostatic charge-discharge test was performed in an oxygen-filled dry container (1 atm) by adopting a CT2001A battery tester (Wuhan blue Power Electronics Co., Ltd.) at room temperature $\left(26{ }^{\circ} \mathrm{C}\right)$. Herein, we mainly focused on exploring carbon loading, discharge rates, discharge depth and air's effect on the 
cycling performance. Lastly, the morphology and composition changes of the discharged or charged products were studied. After disassembling the cell and scraping the cathode surface to remove residual separator glassy fiber, the DME soaked discharged or charged products were vacuum dried for $12 \mathrm{~h}$ and quickly transferred to a gas-tight device to be analyzed by the FE-SEM and XRD measurement (D8 X-ray diffraction Analyzer). A.C. impedance and CV curves were carried out by a CHI660D electrochemical workstation (Shanghai Chenhua Device Company) simultaneously.

\section{Results and discussion}

Table S1. Pore size, pore volume, specific capacity and conductivity data for various carbon aerogels.

\begin{tabular}{|c|c|c|c|c|c|c|c|c|}
\hline $\begin{array}{l}\mathrm{Ca} \\
\mathrm{se}\end{array}$ & $\begin{array}{l}\text { Carbon } \\
\text { aerogel }\end{array}$ & $\begin{array}{l}\text { Resorcin } \\
\text { ol/ } \\
\text { Sodium } \\
\text { carbonat } \\
\text { e }[\mathrm{n} / \mathrm{n}]\end{array}$ & $\begin{array}{l}\text { Reacti } \\
\text { on } \\
\text { mass } \\
\text { ratio } \\
{[\mathrm{w} \%]}\end{array}$ & $\begin{array}{l}\mathrm{S}_{\mathrm{BET}} \\
{\left[\mathrm{m}^{2} / \mathrm{g}\right]}\end{array}$ & $\begin{array}{l}\text { Pore } \\
\text { diamet } \\
\text { er[nm] } \\
\text { BJH } \\
\text { method }\end{array}$ & $\begin{array}{l}\text { Pore } \\
\text { volum } \\
\mathrm{e}[\mathrm{cc} / \mathrm{g} \\
]\end{array}$ & $\begin{array}{l}\text { Avera } \\
\text { ge } \\
\text { pore } \\
\text { diamet } \\
\text { er[nm] }\end{array}$ & $\begin{array}{l}\text { Electri } \\
\text { cal } \\
\text { conduc } \\
\text { tivity[ } \\
\text { S/cm] }\end{array}$ \\
\hline 1 & CRF1000-30 & 1000 & \multirow{3}{*}{30} & 680.22 & 16.00 & 1.06 & 8.46 & 0.502 \\
\hline 2 & CRF1500-30 & 1500 & & 786.87 & 3.15 & 0.68 & 4.87 & 0.323 \\
\hline 3 & CRF2000-30 & 2000 & & 644.47 & 3.13 & 0.37 & 3.29 & 0.336 \\
\hline 4 & CRF1000-40 & 1000 & \multirow{3}{*}{40} & 769.54 & 18.57 & 1.22 & 8.66 & 1.340 \\
\hline 5 & CRF1500-40 & 1500 & & 669.17 & 17.95 & 1.02 & 8.28 & 1.218 \\
\hline 6 & CRF2000-40 & 2000 & & 646.55 & 13.39 & 0.73 & 5.78 & 1.253 \\
\hline
\end{tabular}

Carbon aerogels (see Fig. S2, Fig. S3) with different pore structure were synthesized by using the sol-gel method. As is shown in the Fig. S2 and Fig. S3, all the synthesized aerogels exhibit type-IV isotherms following the IUPAC classification. Especially, there exist hysteresis loops at the high relative pressure above 0.8 , indicating the presence of a great number of meso-pores. All the above six aerogels coating cathodes were used to construct lithium-air batteries, generating several hundred stable cycles (highest for CRF1500-40, 525 cycles; others, no more than 375 cycles) in the galvanostatic charge/discharge cycling. This difference can be attributed to their special nano-porous structure and electrical conductivity. 
Here, two kinds of carbon aerogels, CRF1000-30 and CRF1500-40, with characteristic single and dual pore size distribution, especially possessing extremely similar average mesopore diameter around $8.0 \mathrm{~nm}$, were investigated in detail. At a current density of $0.05 \mathrm{~mA} \mathrm{~cm}{ }^{-2}$ and a fixed capacity of 0.1 mAh, the battery with dual pore and single pore aerogel coating obtains 525 and 332 cycles, respectively. At higher current densities of $0.3,0.5$ and $1.0 \mathrm{~mA} \mathrm{~cm}^{-2}$, cathodes with dual pore structure show 64,33 and 18 cycles comparing to 28,20 and 8 cycles for that of single pore, highlighting the superiority for mass transfer. In addition, the discharge voltage is higher and the charge voltage is lower in the first cycle for the dual pore CRF 1500-40 cathode in all cases, which is apparently shown in the Fig. 4, Fig. S11and Fig. S15. Such sufficient preponderance has a direct relation with CRF150040’s higher electrical conductivity and better mass accessibility (dual pore).

And we postulate that the mass accessibility may be the key factor to determine the electrochemical performance of the lithium-air batteries, originating from the basic results that aerogel CRF 1000-40 owns very similar (even superior) pore parameter and electrical conductivity with (to) CRF 1500-40 but exhibits poor cycling capability (Electrochemical performance data for CRF1000-40 are not shown here.). It is worthwhile to note that the electrical conductivity of the six aerogel cathodes is very close and almost in the same level $(1 \mathbf{S} / \mathbf{c m})$, which can meet the basic use of the active coating materials. Thus, all these demonstrate that dual pore far exceeds single pore for mass transfer. However, among the meso-pores, it needs further study to investigate whether the smaller pore $(3.85$ $\mathrm{nm})$ or larger pore $(17.95 \mathrm{~nm})$ contributes more to the capacity. It is exactly right that these smaller pores may allow better conversion of discharge products during charge, however it initiates pore blockage and inefficient utilization of pore volume (see Fig. 4(d)). The smaller pores are apt to absorb and be filled with electrolyte due to capillarity, thus causing mass migrating obstacles. Conversely, the larger meso-pores would be feasible for oxygen and lithium ions transfer. As for the problem of thick layer discharge products (cathode passiviation), one can adjust it by limiting the discharge capacity. At 
last, we conclude that the dual pore improves the mass transfer and enhances the high discharge rate capability.

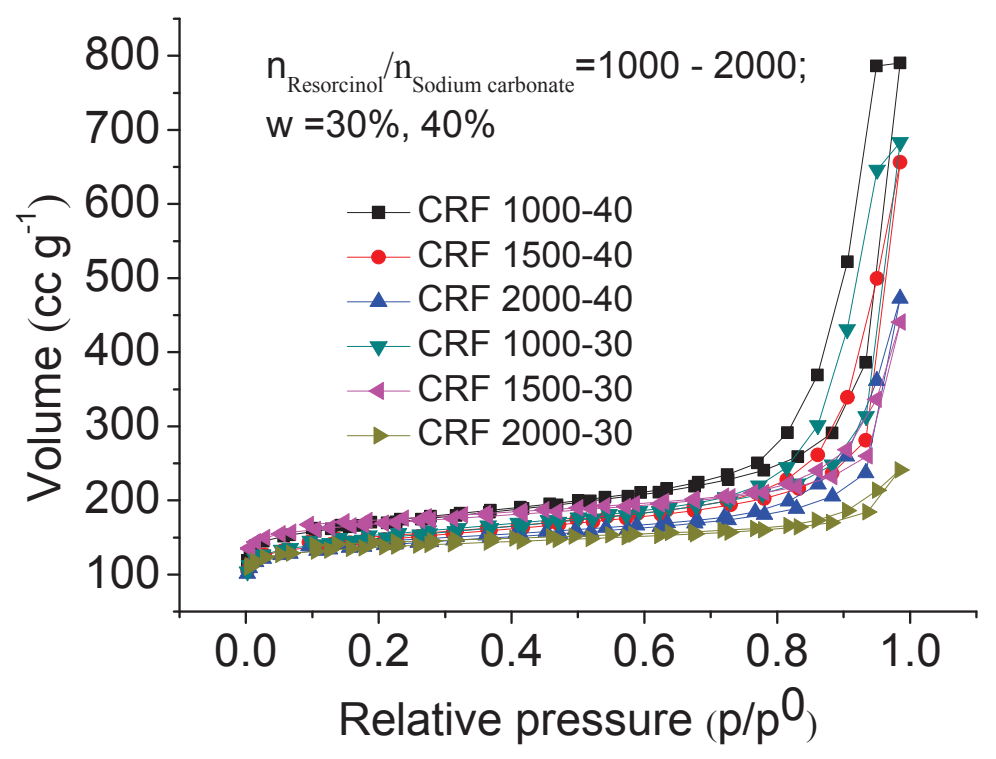

Fig. S2. $\mathrm{N}_{2}$ adsorption-desorption isotherms of carbon aerogel with different reactant/catalyst molar ratio ranging from 1000 to 2000 at a low temperature of $77 \mathrm{~K}$.

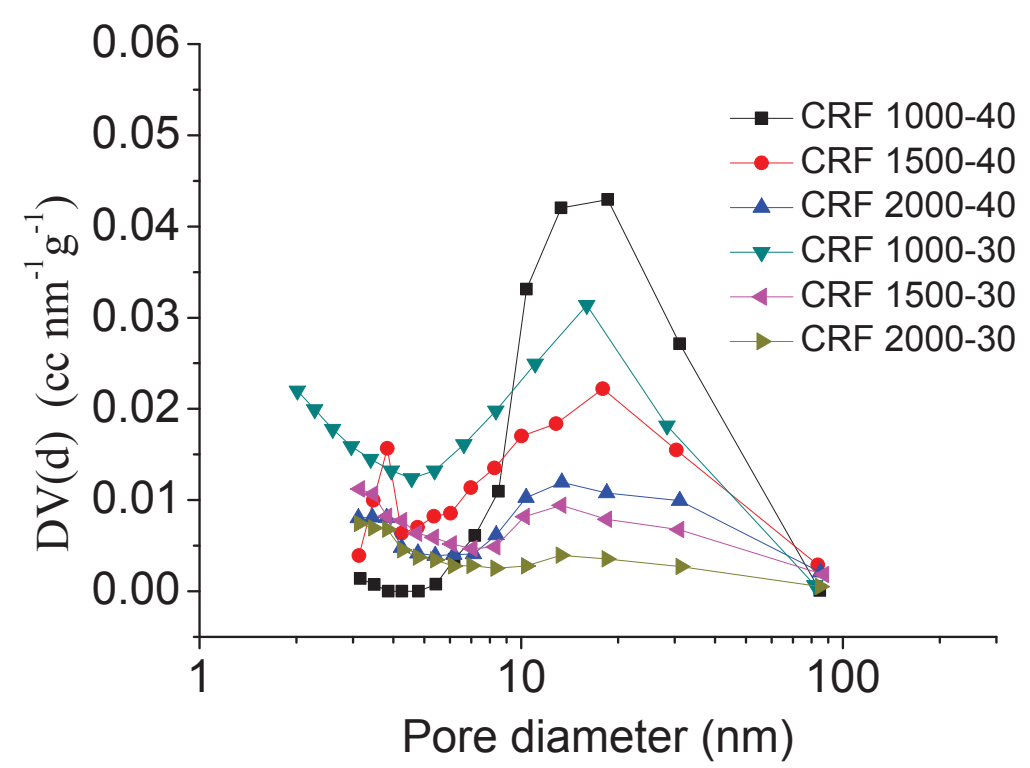

Fig. S3. BJH pore size distribution graph of carbon aerogels with different reactant/catalyst molar ratio varying from 1000 to 2000 . 


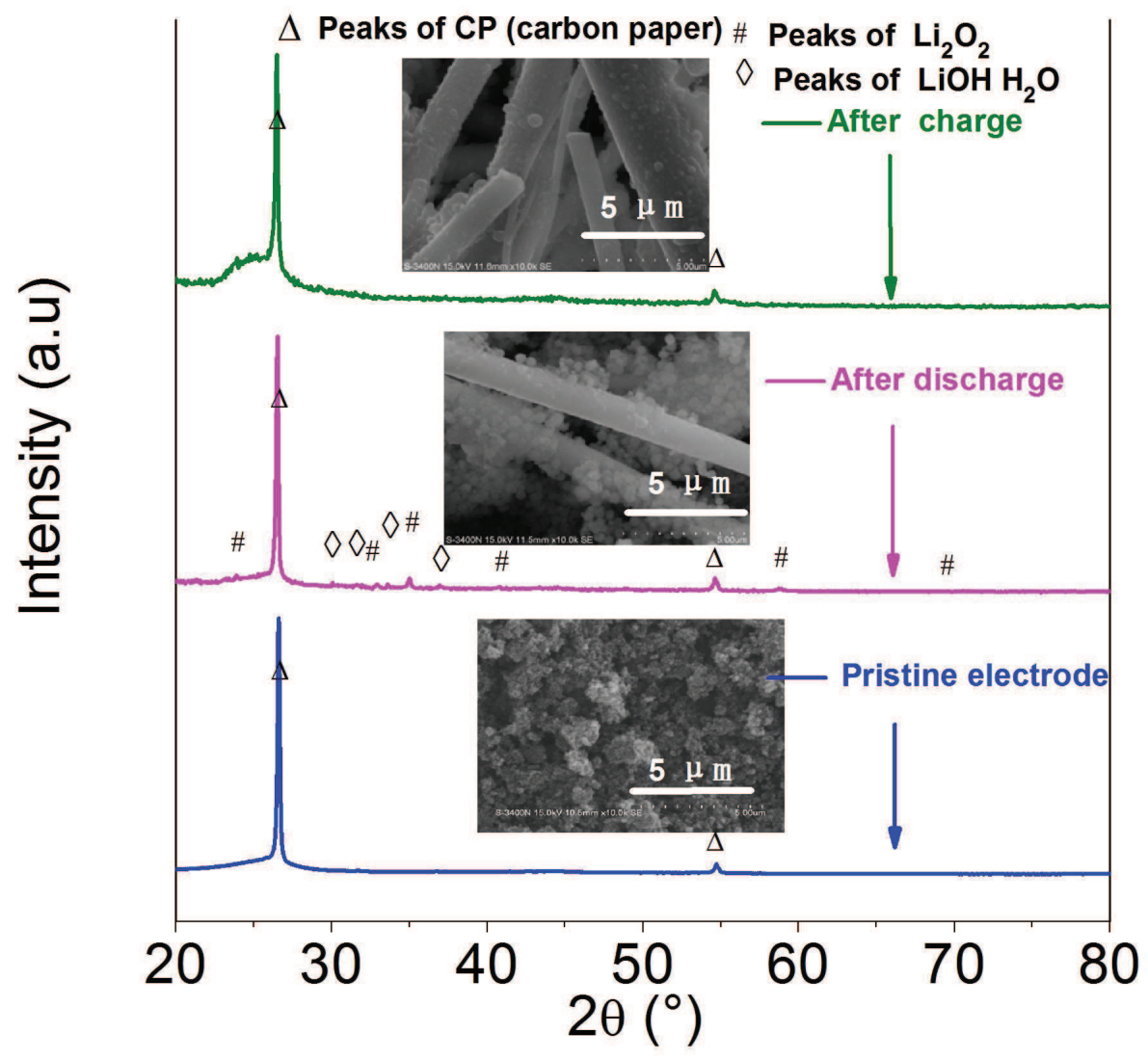

Fig. S4. XRD patterns and SEM test of the pristine and discharged/charged cathode (CRF1000-30) with a carbon loading of $0.4 \mathrm{mg}$ after 10 th cycle. The current density is $0.10 \mathrm{~mA} \mathrm{~cm}$.

Table S2. The variation of cycling performance with different carbon loadings when CRF1500-40 is used as cathode active material in the oxygen environment.

\begin{tabular}{|c|c|c|c|c|c|c|}
\hline Cathode & $\begin{array}{c}\text { Electrolyt } \\
\mathrm{e}\end{array}$ & $\begin{array}{c}\text { Carbon } \\
\text { loading/m } \\
\mathrm{g}\end{array}$ & $\begin{array}{c}\text { Current } \\
\text { density/m } \\
\mathrm{A} \mathrm{cm}^{-2}\end{array}$ & $\begin{array}{c}\text { Specific } \\
\text { capacity } \\
/ \mathrm{mAh} \\
\mathrm{g}^{-1}\end{array}$ & $\begin{array}{l}\text { Capacity/ } \\
\text { mAh }\end{array}$ & $\begin{array}{l}\text { Cycling } \\
\text { number }\end{array}$ \\
\hline $\begin{array}{l}\text { Carbon } \\
\text { paper }\end{array}$ & \multirow{7}{*}{$\begin{array}{c}1 \mathrm{M} \\
\text { LiTFSI/ } \\
\text { sulfolane }\end{array}$} & 0.1 & \multirow{7}{*}{0.05} & \multirow{7}{*}{1000} & 0.1 & 363 \\
\hline \multirow{6}{*}{$\begin{array}{l}\text { CRF1500- } \\
40+p V d F= \\
9: 1\end{array}$} & & 0.1 & & & 0.1 & 525 \\
\hline & & 0.2 & & & 0.2 & 230 \\
\hline & & 0.3 & & & 0.3 & 150 \\
\hline & & 0.4 & & & 0.4 & 100 \\
\hline & & 0.5 & & & 0.5 & 90 \\
\hline & & 0.6 & & & 0.6 & 78 \\
\hline
\end{tabular}



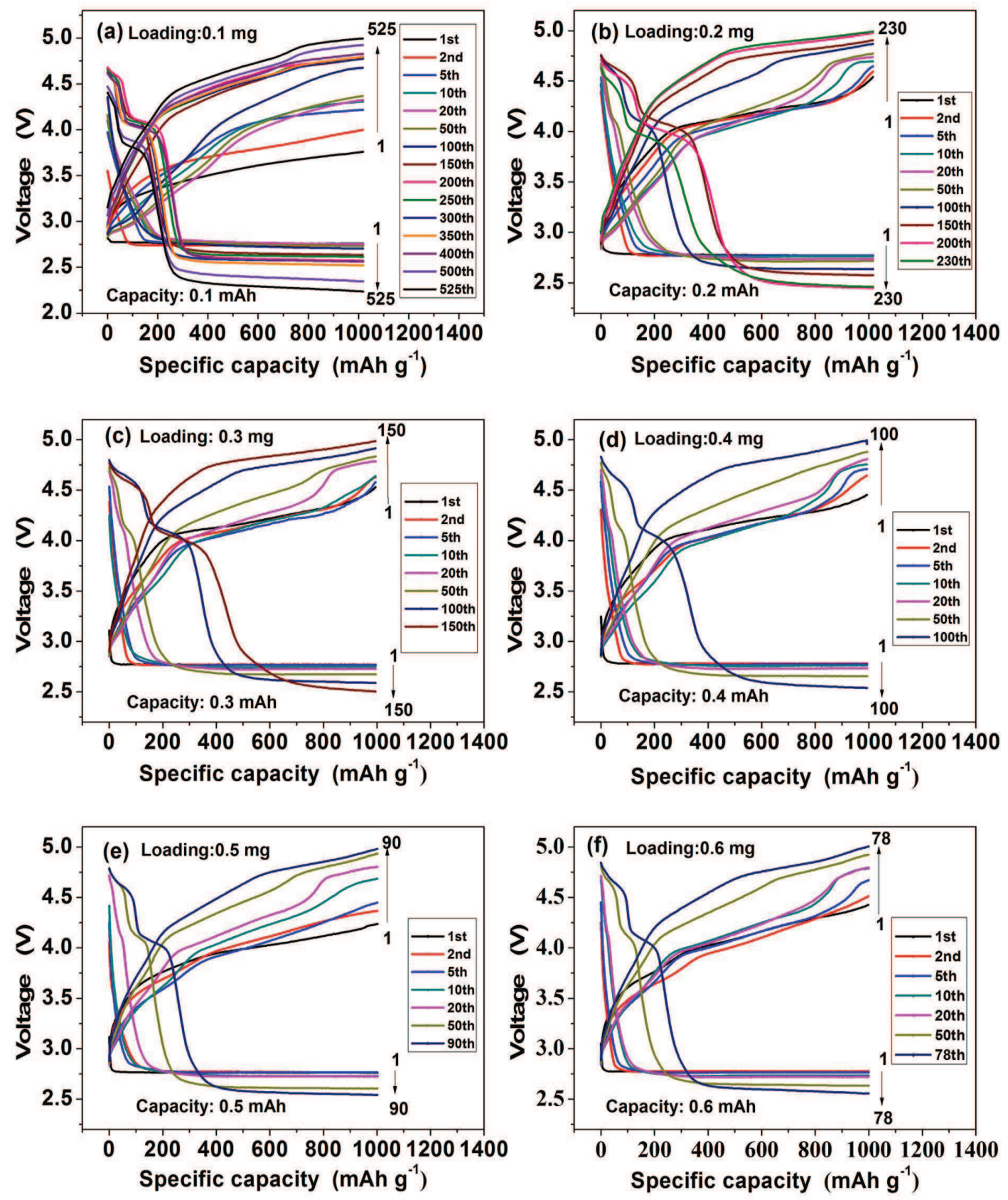

Fig. S5. Discharge-charge curves of the lithium-air batteries with a CRF1500-40 carbon cathode of various loadings at different cycles. 1M LiTFSI/sulfolane is used as electrolyte; The current density is $0.05 \mathrm{~mA} \mathrm{~cm}^{-2}$ and specific capacity is $1000 \mathrm{mAh} \mathrm{g}^{-1}$. The carbon loading in Fig. S5.(a-f) is ranging from $0.1 \mathrm{mg}$ to $0.6 \mathrm{mg}$.

Herein, the specific energy and energy efficiency of the carbon aerogel (CRF1500-40) carbon 
cathode composed lithium-air batteries were also investigated during the discharge and charge process. As is shown in Fig. S6, for most cases, the discharge specific energy was above $2750 \mathrm{Wh} \mathrm{Kg}^{-1}$ while the charge specific energy was in the range of $3620 \mathrm{Wh} \mathrm{Kg}^{-1}$ to $4792 \mathrm{Wh} \mathrm{Kg}^{-1}$, resulting in a relative high energy efficiency varying from $57.38 \%$ to $78.32 \%$ even though on the condition of encountering unstable disturbance (open the dry testing container to take out batteries for discharged or charged products analysis) or long term test above 400 cycles. Such high discharge specific energy and energy efficiency compared well with that $(65 \%$ or $62.5 \%)$ previous reported. $[9,12]$

The final and median voltages in the discharge and charge process at various cycles were analyzed synchronously. Final voltage (FV) refers to charge or discharge voltage at the end of a charge or discharge process. MV can reflect the average value of voltages (MV is not the average voltage, but relatively close to the average voltage). FV can reflect the lowest discharge voltage and the highest charge voltage during a cycle. [35] Fig. S7 revealed that the final discharge voltage was above $2.5 \mathrm{~V}$, which was similar to the median discharge voltage. The median charge voltage was below $4.75 \mathrm{~V}$ for all the cases in the initial 78 (Fig. S7 (e, f)) or 100 cycles (Fig. S7 (a-d)) before the final charge voltage reached 5.0 V (cut off voltage). The flat high discharge voltage plateau demonstrated stable electrochemical reaction in the lithium-air batteries and relative low polarization of cathode structure. However, the superior performance didn't maintain for a long time before the charge voltage soared to 5.0 V, which might have a direct relation with the pore blockage, cathode passivation and side reactions during discharge and charge process. The following impedance test and XRD test rendered the concrete proof (see Fig. S8, Fig. S9, Fig. S10 and Fig. S14). 

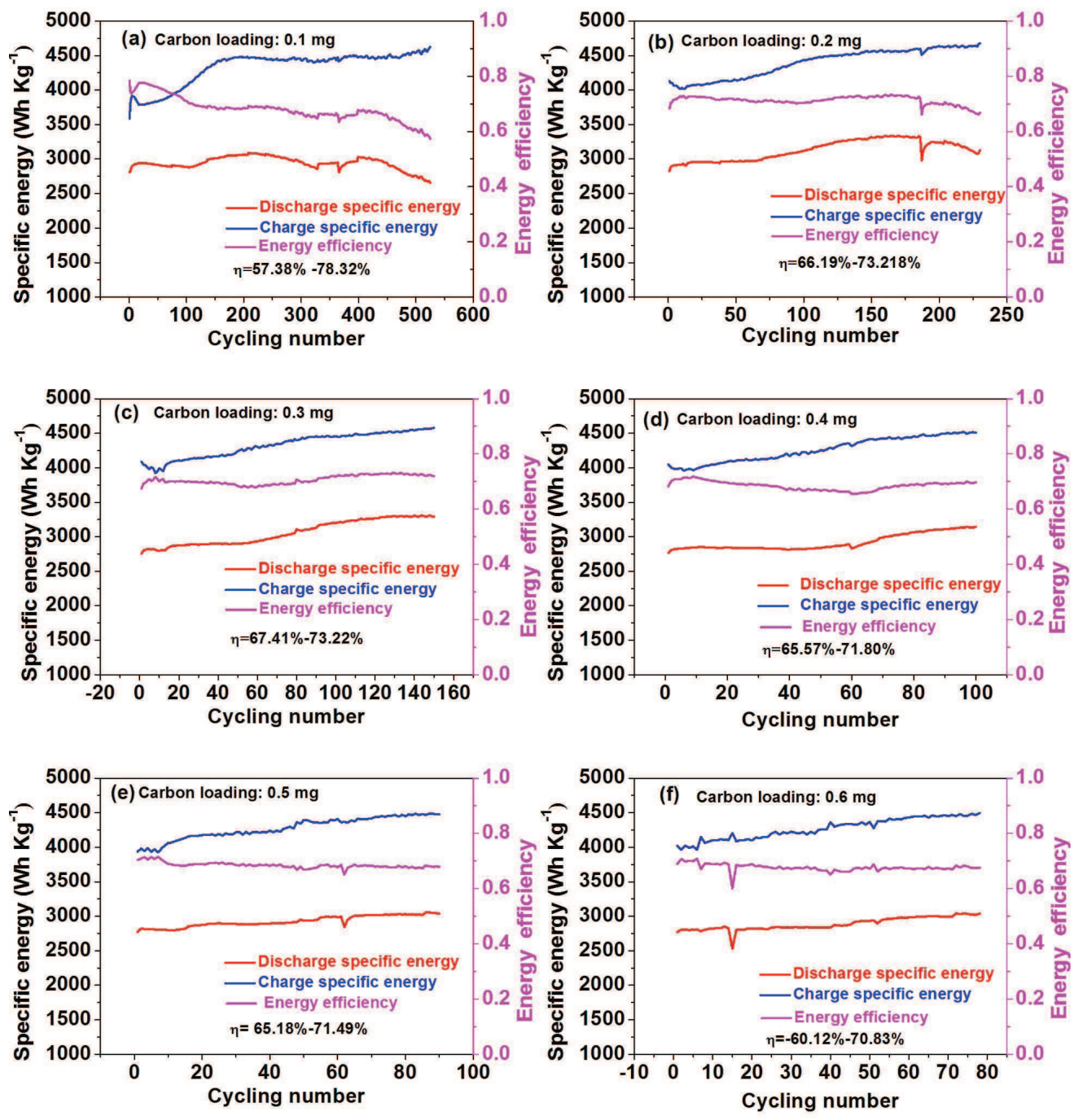

Fig. S6. Specific energy and energy efficiency of lithium-air batteries that contain $1 \mathrm{M}$ LiTFSI/sulfolane based electrolyte after discharge and charge. All the CRF1500-40 carbon aerogel carbon cathodes have different carbon loadings, varying from $0.1 \mathrm{mg}$ to $0.6 \mathrm{mg}$ (see Fig. S6 (a-f) ). 

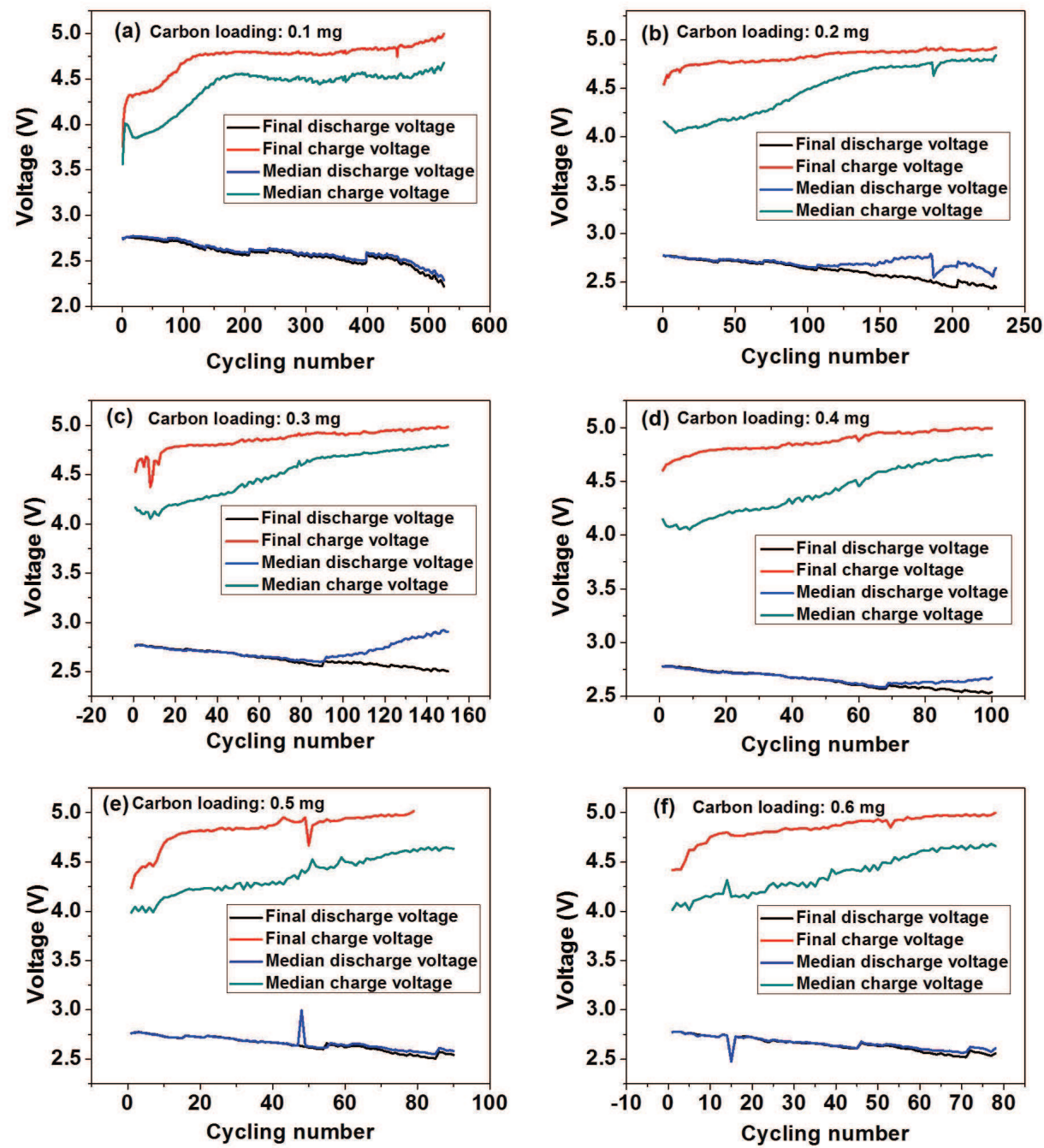

Fig. S7. Median and final voltages of lithium-air batteries that contain $1 \mathrm{M} \mathrm{LiTFSI/sulfolane} \mathrm{based}$ electrolyte after discharge and charge. All the CRF1500-40 (carbon aerogel) carbon cathodes have different carbon loading, varying from $0.1 \mathrm{mg}$ to $0.6 \mathrm{mg}(\mathbf{F i g} . \mathbf{S 7}(\mathbf{a}-\mathbf{f})$ ). 

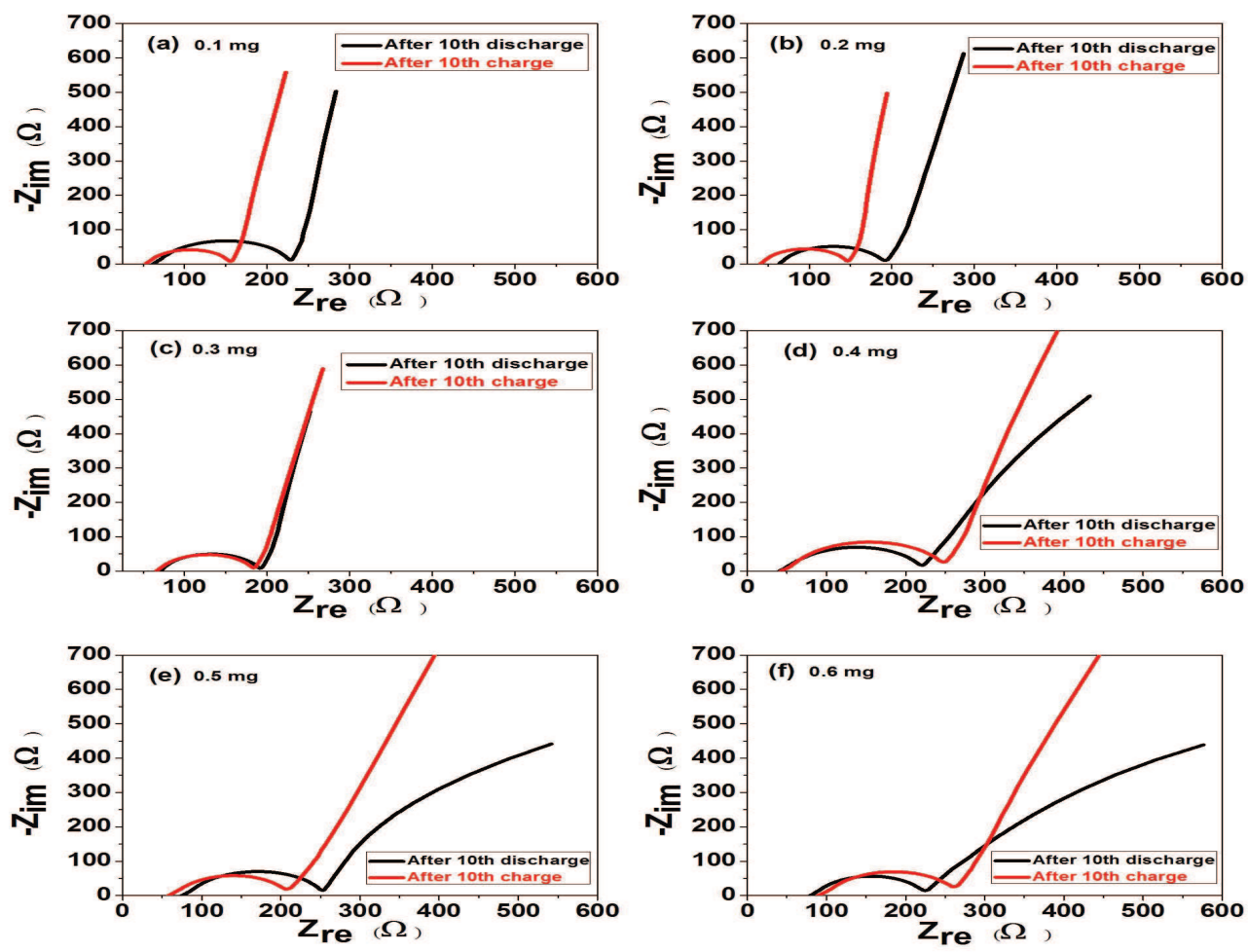

Fig. S8. Impedance spectra of the lithium-air batteries with different carbon loadings composed CRF1500-40 air cathode after 10th discharge/charge.

After various galvanostatic discharge/charge cycling, electrolyte ohmic resistance, interfacial resistance, charge transfer resistance all incline to increase during the discharge process and drop in the subsequent charge process except the case of aerogel loading of $0.4 \mathrm{mg}$ and $0.6 \mathrm{mg}$. That may be ascribed to: 1) the manual assembly processes of different batteries are hardly to be completely identical; 2) the process of taking battery out of the sealed and dried testing box for electrochemical impedance test, SEM and XRD test may penetrate water and carbon dioxide, resulting in a fluctuating environment. If this just happens at a discharge state (for $0.4 \mathrm{mg}, 0.6 \mathrm{mg}$ ), then great impedance changes may occur. It's highlighted that charge transfer resistance occupies the main part of the three resistance distribution, which has direct connection with the accumulation of low electrical conductivity discharged products of $\mathrm{Li}_{2} \mathrm{O}_{2}$ in the cathode. For the abnormal interfacial resistance increase during the charge process, it has somethings to do with the unimitate contact with the current collector due to cathode expansion in the previous discharging process. 
Table S3. Dependence of equivalent-circuit parameters upon the porosity of CRF1500-40 cathode with a carbon loading ranging from $0.1 \mathrm{mg}$ to $0.6 \mathrm{mg}$ after 10th discharg/charge cycles. All the meanings of the subscripts for the resistance can be seen the Table S4 below.

\begin{tabular}{|c|c|c|c|c|c|c|c|c|c|c|c|}
\hline \multirow{2}{*}{\multicolumn{2}{|c|}{$\begin{array}{l}\text { Carbon } \\
\text { Loading } \\
(\mathrm{mg})\end{array}$}} & \multirow{2}{*}{$\begin{array}{l}\operatorname{Re}(\Omega \\
\left.\mathrm{cm}^{-2}\right)\end{array}$} & \multicolumn{2}{|c|}{$\mathrm{C}_{\text {int }}\left(\mathrm{F} \mathrm{cm}^{-2}\right)$} & \multirow{2}{*}{$\begin{array}{c}\mathrm{R}_{\text {int }}(\Omega \\
\left.\mathrm{cm}^{-2}\right)\end{array}$} & \multicolumn{2}{|c|}{$\mathrm{C}_{\mathrm{m}}\left(\mathrm{F} \mathrm{cm}^{-2}\right)$} & \multirow{2}{*}{$\begin{array}{c}\mathrm{R}_{\mathrm{ct}}(\Omega \\
\left.\mathrm{cm}^{-2}\right)\end{array}$} & \multicolumn{3}{|c|}{$\mathrm{W}_{\mathrm{O}}\left(\Omega \mathrm{cm}^{-2}\right)$} \\
\hline & & & $\mathrm{C}_{\text {int- } \mathrm{T}}$ & $\mathrm{C}_{\text {int-P }}$ & & $\mathrm{C}_{\mathrm{m}-\mathrm{T}}$ & $\mathrm{C}_{\mathrm{m}-\mathrm{P}}$ & & $\begin{array}{c}\mathrm{W}_{\mathrm{O}-} \\
\mathrm{R}\end{array}$ & $\begin{array}{c}\mathrm{W}_{\mathrm{O}-} \\
\mathrm{T}\end{array}$ & $\begin{array}{c}\mathrm{W}_{\mathrm{O}} \\
\mathrm{P}\end{array}$ \\
\hline \multirow{6}{*}{$\begin{array}{l}\text { After } \\
10 \text { th } \\
\text { disch } \\
\text { arge }\end{array}$} & 0.1 & 61.23 & $\begin{array}{l}6.647 \\
9 \\
\times 10^{-4} \\
\end{array}$ & $\begin{array}{l}542 \\
62 \times \\
10^{-3} \\
\end{array}$ & 49.77 & $\begin{array}{l}2.98 \\
2 \times \\
10^{-5} \\
\end{array}$ & $\begin{array}{c}958 . \\
3 \times \\
10^{-3} \\
\end{array}$ & 121.4 & $\begin{array}{c}1.61 \\
4\end{array}$ & $\begin{array}{l}30.3 \\
3 \times \\
10^{-3} \\
\end{array}$ & $\begin{array}{l}460 . \\
84 \times \\
10^{-3} \\
\end{array}$ \\
\hline & 0.2 & 63.5 & $\begin{array}{l}19.70 \\
7 \times \\
10^{-5}\end{array}$ & $\begin{array}{l}713 \\
58 \times \\
10^{-3}\end{array}$ & 18.05 & $\begin{array}{l}2.34 \\
35 \times \\
10^{-5}\end{array}$ & $\begin{array}{l}957 . \\
24 \times \\
10^{-3}\end{array}$ & 102.2 & $\begin{array}{c}36.9 \\
4\end{array}$ & $\begin{array}{l}671 . \\
06 \times \\
10^{-3}\end{array}$ & $\begin{array}{l}444 . \\
96 \times \\
10^{-3}\end{array}$ \\
\hline & 0.3 & 71.23 & $\begin{array}{l}19.48 \\
6 \times \\
10^{-5} \\
\end{array}$ & $\begin{array}{l}745 . \\
94 \times \\
10^{-3}\end{array}$ & 14.64 & $\begin{array}{l}2.23 \\
93 \times \\
10^{-5}\end{array}$ & $\begin{array}{l}950 . \\
17 \times \\
10^{-3}\end{array}$ & 100.4 & $\begin{array}{c}25.3 \\
8\end{array}$ & $\begin{array}{l}650 . \\
28 \times \\
10^{-3} \\
\end{array}$ & $\begin{array}{l}456 . \\
44 \times \\
10^{-3}\end{array}$ \\
\hline & 0.4 & 40.77 & $\begin{array}{l}49.11 \\
7 \times \\
10^{-5}\end{array}$ & $\begin{array}{l}583 . \\
19 \times \\
10^{-3} \\
\end{array}$ & 30.71 & $\begin{array}{l}5.82 \\
62 \times \\
10^{-5} \\
\end{array}$ & $\begin{array}{l}920 . \\
94 \times \\
10^{-3} \\
\end{array}$ & 146.3 & 6.35 & $\begin{array}{l}56.9 \\
15 \times \\
10^{-3} \\
\end{array}$ & $\begin{array}{l}393 . \\
12 \times \\
10^{-3}\end{array}$ \\
\hline & 0.5 & 75.81 & $\begin{array}{l}22.56 \\
2 \times \\
10^{-5} \\
\end{array}$ & $\begin{array}{l}650 . \\
97 \times \\
10^{-3} \\
\end{array}$ & 22.88 & $\begin{array}{l}3.43 \\
04 \times \\
10^{-5} \\
\end{array}$ & $\begin{array}{l}946 . \\
22 \times \\
10^{-3}\end{array}$ & 147.2 & $\begin{array}{c}4.26 \\
1\end{array}$ & $\begin{array}{l}23.5 \\
14 \times \\
10^{-3} \\
\end{array}$ & $\begin{array}{l}366 . \\
84 \times \\
10^{-3}\end{array}$ \\
\hline & 0.6 & 80.45 & $\begin{array}{l}28.38 \\
5 \times \\
10^{-5} \\
\end{array}$ & $\begin{array}{l}665 . \\
39 \times \\
10^{-3}\end{array}$ & 23.01 & $\begin{array}{l}4.69 \\
59 \times \\
10^{-5} \\
\end{array}$ & $\begin{array}{c}968 . \\
1 \times \\
10^{-3} \\
\end{array}$ & 115.1 & $\begin{array}{c}129 \\
0\end{array}$ & $\begin{array}{c}60.9 \\
9\end{array}$ & $\begin{array}{l}687 . \\
34 \times \\
10^{-3}\end{array}$ \\
\hline \multirow{6}{*}{$\begin{array}{l}\text { After } \\
10 \text { th } \\
\text { charg } \\
\mathrm{e}\end{array}$} & 0.1 & 40.81 & $\begin{array}{r}24.06 \\
\times 10^{-5}\end{array}$ & $\begin{array}{l}719 . \\
89 \times \\
10^{-3} \\
\end{array}$ & 14.96 & $\begin{array}{l}3.01 \\
48 \times \\
10^{-5} \\
\end{array}$ & $\begin{array}{l}977 . \\
53 \times \\
10^{-3}\end{array}$ & 85.1 & $\begin{array}{l}29.8 \\
7\end{array}$ & $\begin{array}{l}750 . \\
61 \times \\
10^{-3} \\
\end{array}$ & $\begin{array}{l}463 \\
\times \\
10^{-3} \\
\end{array}$ \\
\hline & 0.2 & 40.81 & $\begin{array}{l}24.06 \\
4 \times \\
10^{-5}\end{array}$ & $\begin{array}{l}719 . \\
89 \times \\
10^{-3}\end{array}$ & 14.96 & $\begin{array}{l}3.01 \\
48 \times \\
10^{-5}\end{array}$ & $\begin{array}{l}977 . \\
53 \times \\
10^{-3}\end{array}$ & 85.1 & $\begin{array}{c}29.8 \\
7\end{array}$ & $\begin{array}{l}750 \\
61 \times \\
10^{-3}\end{array}$ & $\begin{array}{c}463 \\
\times \\
10^{-3}\end{array}$ \\
\hline & 0.3 & 65.65 & $\begin{array}{l}62.48 \\
7 \times \\
10^{-5}\end{array}$ & $\begin{array}{c}575 . \\
1 \times \\
10^{-3}\end{array}$ & 38.13 & $\begin{array}{l}2.71 \\
13 \times \\
10^{-5} \\
\end{array}$ & $\begin{array}{c}958 . \\
7 \times \\
10^{-3}\end{array}$ & 82.83 & $\begin{array}{c}1.11 \\
8\end{array}$ & $\begin{array}{l}14.7 \\
6 \times \\
10^{-3}\end{array}$ & $\begin{array}{c}450 . \\
3 \times \\
10^{-3}\end{array}$ \\
\hline & 0.4 & 40.83 & $\begin{array}{l}169.5 \\
8 \times \\
10^{-5}\end{array}$ & $\begin{array}{l}421 . \\
48 \times \\
10^{-3} \\
\end{array}$ & 43.23 & $\begin{array}{l}5.97 \\
61 \times \\
10^{-5} \\
\end{array}$ & $\begin{array}{l}942 . \\
95 \times \\
10^{-3}\end{array}$ & 168.5 & $\begin{array}{c}7.23 \\
6\end{array}$ & $\begin{array}{l}68.1 \\
72 \times \\
10^{-3} \\
\end{array}$ & $\begin{array}{l}436 . \\
13 \times \\
10^{-3} \\
\end{array}$ \\
\hline & 0.5 & 57.83 & $\begin{array}{l}78.01 \\
9 \times \\
10^{-5}\end{array}$ & $\begin{array}{l}528 \\
86 \times \\
10^{-3} \\
\end{array}$ & 56.69 & $\begin{array}{l}5.79 \\
29 \times \\
10^{-5} \\
\end{array}$ & $\begin{array}{l}976 . \\
16 \times \\
10^{-3}\end{array}$ & 96.83 & 5.69 & $\begin{array}{l}41.9 \\
54 \times \\
10^{-3} \\
\end{array}$ & $\begin{array}{l}413 . \\
88 \times \\
10^{-3}\end{array}$ \\
\hline & 0.6 & 89.49 & $\begin{array}{l}70.00 \\
6 \times \\
10^{-5}\end{array}$ & $\begin{array}{c}522 . \\
6 \times \\
10^{-3}\end{array}$ & 35.19 & $\begin{array}{l}5.28 \\
61 \times \\
10^{-5}\end{array}$ & $\begin{array}{l}951 \\
32 \times \\
10^{-3}\end{array}$ & 135.7 & $\begin{array}{c}10.0 \\
3\end{array}$ & $\begin{array}{l}53.4 \\
16 \times \\
10^{-3}\end{array}$ & $\begin{array}{l}417 \\
82 \times \\
10^{-3}\end{array}$ \\
\hline
\end{tabular}




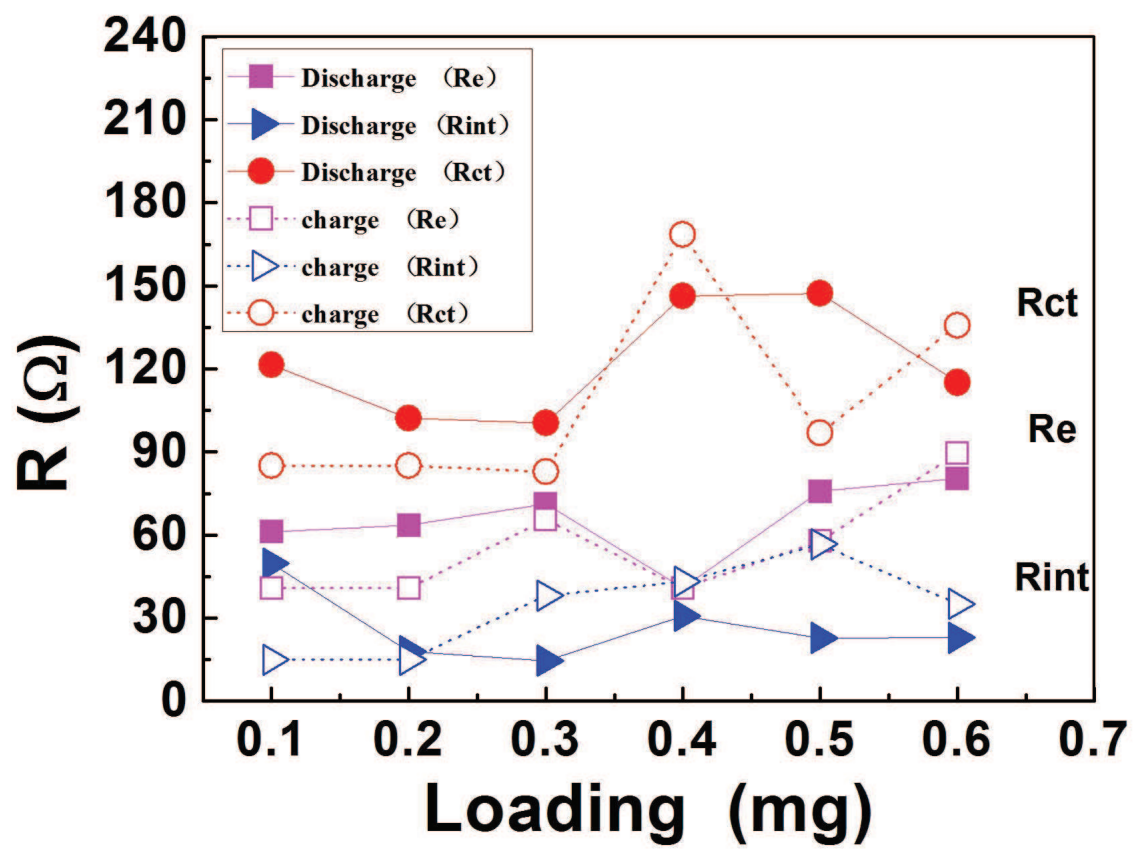

Fig. S9. The variation of the resistance distribution with the increase of cathode carbon loading in the lithium-air batteries after 10th discharge/charge. Re, Rint and Rct are on behalf of the electrolyte ohmic resistance, interfacial resistance, charge transfer resistance, respectively.
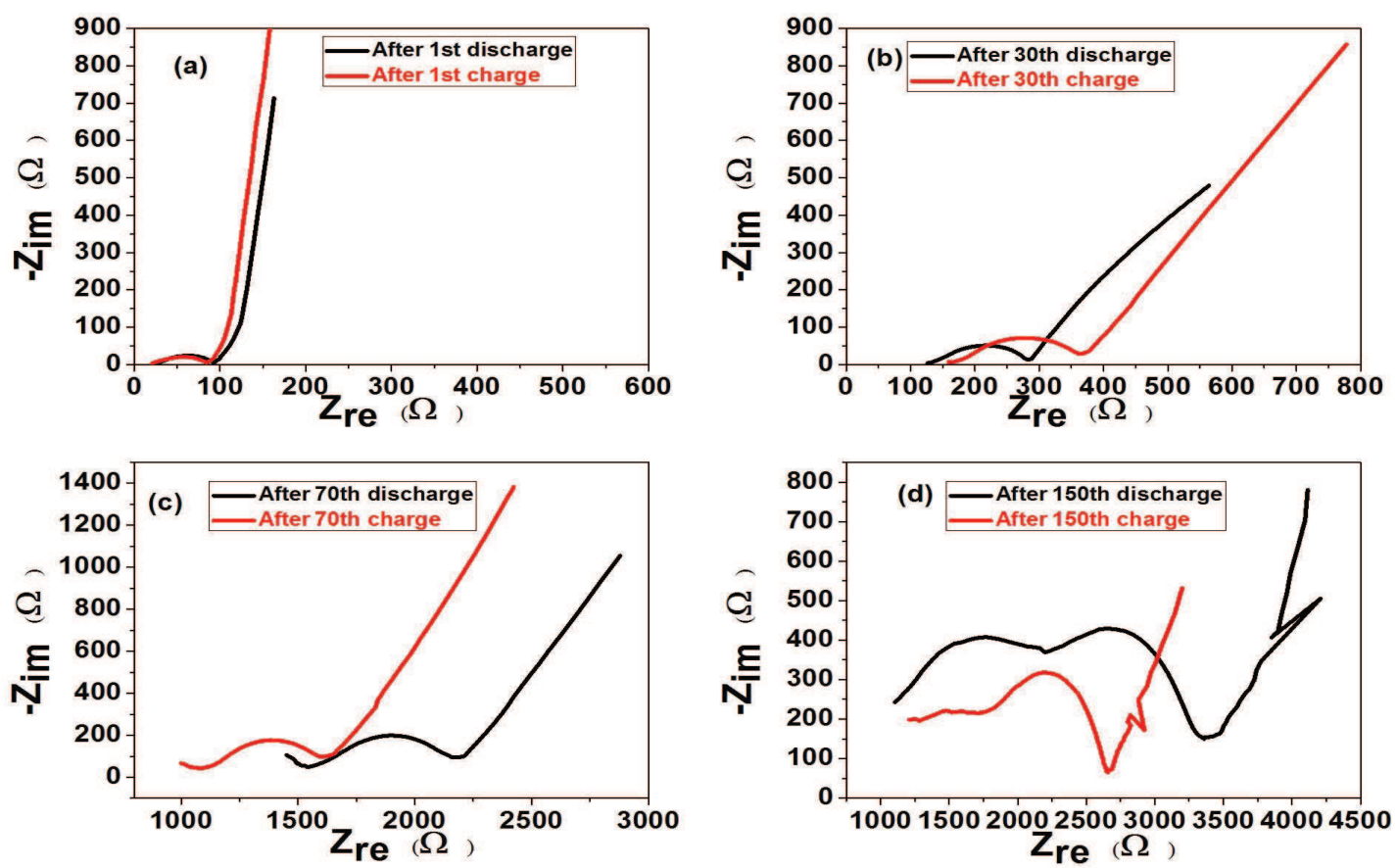

Fig. S10. Impedance spectra of lithium-air batteries at various cyclings after discharge/charge. All the cases were based on the CRF1500-40 air cathode with a carbon loading of $0.4 \mathrm{mg}$, a limited specific 
capacity of $1000 \mathrm{mAh} \mathrm{g}^{-1}$ and the current density of $0.05 \mathrm{~mA} \mathrm{~cm}^{-2}$. Fig. $\mathbf{S 1 0}$ (a-d) corresponded to 1st, 30th, 70th, 150th cycle after discharge/charge, respectively. 10th and 100th cycle after discharge/ charge were shown in Fig. S8 and Fig. 5 (d) separately.

Table S4. Dependence of equivalent-circuit parameters upon the porosity of CRF1500-40 cathode with a carbon loading of $0.4 \mathrm{mg}$ at the initial state and discharged state for various cycles.

\begin{tabular}{|c|c|c|c|c|c|c|c|c|c|c|}
\hline \multirow{2}{*}{$\begin{array}{l}\text { Carbon } \\
(0.4 \mathrm{mg})\end{array}$} & \multirow{2}{*}{$\begin{array}{l}\operatorname{Re}(\Omega \\
\left.\mathrm{cm}^{-2}\right)\end{array}$} & \multicolumn{2}{|c|}{$\mathrm{C}_{\text {int }}\left(\mathrm{F} \mathrm{cm}^{-2}\right)$} & \multirow{2}{*}{$\begin{array}{c}\mathrm{R}_{\text {int }}(\Omega \\
\left.\mathrm{cm}^{-2}\right)\end{array}$} & \multicolumn{2}{|c|}{$\mathrm{C}_{\mathrm{m}}\left(\mathrm{F} \mathrm{cm}^{-2}\right)$} & \multirow{2}{*}{$\begin{array}{l}\mathrm{R}_{\mathrm{ct}}(\Omega \\
\left.\mathrm{cm}^{-2}\right)\end{array}$} & \multicolumn{3}{|c|}{$\mathrm{W}_{\mathrm{O}}\left(\Omega \mathrm{cm}^{-2}\right)$} \\
\hline & & $\mathrm{C}_{\text {int- } \mathrm{T}}$ & $\mathrm{C}_{\text {int-P }}$ & & $\mathrm{C}_{\mathrm{m}-\mathrm{T}}$ & $\mathrm{C}_{\mathrm{m}-\mathrm{P}}$ & & $\begin{array}{c}\mathrm{W}_{\mathrm{O}-} \\
\mathrm{R}\end{array}$ & $\begin{array}{c}\mathrm{W}_{\mathrm{O}-} \\
\mathrm{T}\end{array}$ & $\begin{array}{c}\mathrm{W}_{\mathrm{O}-} \\
\mathrm{P}\end{array}$ \\
\hline $\begin{array}{c}\text { CRF150 } \\
0-40\end{array}$ & 13.60 & $\begin{array}{l}32.96 \\
\times 10^{-3}\end{array}$ & $\begin{array}{l}664 . \\
66 \times \\
10^{-3}\end{array}$ & 45.88 & $\begin{array}{l}877 \\
05 \times \\
10^{-4}\end{array}$ & $\begin{array}{l}675 \\
18 \times \\
10^{-3}\end{array}$ & 31.18 & $\begin{array}{l}133 . \\
85 \times \\
10^{-3}\end{array}$ & $\begin{array}{l}285 \\
29 \times \\
10^{-5}\end{array}$ & $\begin{array}{l}493 . \\
73 \times \\
10^{-3}\end{array}$ \\
\hline $1^{\text {st }}$ & 25.69 & $\begin{array}{l}2.604 \\
\times 10^{-5}\end{array}$ & $\begin{array}{l}821 \\
76 \times \\
10^{-3}\end{array}$ & 14.34 & $\begin{array}{l}1.87 \\
28 \times \\
10^{-5}\end{array}$ & $\begin{array}{l}983 \\
37 \times \\
10^{-3}\end{array}$ & 45.41 & $\begin{array}{c}47.3 \\
9\end{array}$ & $\begin{array}{c}779 \\
5 \times \\
10^{-3}\end{array}$ & $\begin{array}{l}449 . \\
92 \times \\
10^{-3}\end{array}$ \\
\hline 10th & 40.77 & $\begin{array}{l}49.11 \\
7 \times \\
10^{-5}\end{array}$ & $\begin{array}{c}583 \\
19 \times \\
10^{-3}\end{array}$ & 30.71 & $\begin{array}{l}5.82 \\
62 \times \\
10^{-5}\end{array}$ & $\begin{array}{l}920 \\
94 \times \\
10^{-3}\end{array}$ & 146.3 & $\begin{array}{c}6.34 \\
8\end{array}$ & $\begin{array}{l}56.9 \\
15 \times \\
10^{-3}\end{array}$ & $\begin{array}{l}393 . \\
12 \times \\
10^{-3}\end{array}$ \\
\hline 30 th & 134.2 & $\begin{array}{l}17.13 \\
2 \times \\
10^{-3}\end{array}$ & $\begin{array}{l}836 \\
58 \times \\
10^{-3}\end{array}$ & 174.9 & $\begin{array}{l}8.06 \\
56 \times \\
10^{-5}\end{array}$ & $\begin{array}{l}697 . \\
87 \times \\
10^{-3}\end{array}$ & 156.5 & $\begin{array}{l}3.19 \\
43 \times \\
10^{-6}\end{array}$ & $\begin{array}{l}661 . \\
04 \times \\
10^{-3}\end{array}$ & $\begin{array}{l}308 . \\
86 \times \\
10^{-3}\end{array}$ \\
\hline 70th & 610.5 & $\begin{array}{l}6.054 \\
2 \times \\
10^{-5}\end{array}$ & $\begin{array}{l}87.7 \\
65 \times \\
10^{-3}\end{array}$ & 848.6 & $\begin{array}{l}2.30 \\
47 \times \\
10^{-5}\end{array}$ & $\begin{array}{l}845 \\
21 \times \\
10^{-3}\end{array}$ & 799.7 & $\begin{array}{c}17.1 \\
8\end{array}$ & $\begin{array}{l}23.0 \\
44 \times \\
10^{-3}\end{array}$ & $\begin{array}{l}327 . \\
44 \times \\
10^{-3}\end{array}$ \\
\hline 100th & 521.6 & $\begin{array}{l}4.901 \\
4 \times \\
10^{-7}\end{array}$ & $\begin{array}{l}746 . \\
49 \times \\
10^{-3}\end{array}$ & 876.5 & $\begin{array}{l}5.11 \\
78 \times \\
10^{-6} \\
\end{array}$ & $\begin{array}{l}835 . \\
89 \times \\
10^{-3}\end{array}$ & 970.4 & $\begin{array}{c}208 . \\
49\end{array}$ & $\begin{array}{c}34.5 \\
6\end{array}$ & $\begin{array}{c}518 . \\
8 \times \\
10^{-3}\end{array}$ \\
\hline 150th & 938.7 & $\begin{array}{l}8.561 \\
6 \times \\
10^{-7}\end{array}$ & $\begin{array}{l}630 \\
16 \times \\
10^{-3}\end{array}$ & 1400 & $\begin{array}{l}5.45 \\
08 \times \\
10^{-6}\end{array}$ & $\begin{array}{l}805 \\
31 \times \\
10^{-3}\end{array}$ & 914.6 & $\begin{array}{c}156 . \\
5\end{array}$ & $\begin{array}{c}38.4 \\
3\end{array}$ & $\begin{array}{l}333 . \\
62 \times \\
10^{-3}\end{array}$ \\
\hline
\end{tabular}

Note: $\mathrm{Re}, \mathrm{R}_{\text {int }}, \mathrm{R}_{\mathrm{ct}}$ are electrolyte ohmic resistance, interfacial resistance, charge transfer resistance, respectively. $\mathrm{CPE}$ is constant phase element, and $\mathrm{C}_{\mathrm{int}}$ is typical of surface films formed on the electrode. $\mathrm{C}_{\mathrm{m}}$ is double-layer capacitance distributed between the ohmic and faradaic processes. $\mathrm{W}_{\mathrm{o}}$ is finite length Warburg resistance (open-circuit terminus), on behalf of kinetic resistance for oxygen and $\mathrm{Li}^{+}$. The subscripts of $\mathrm{R}, \mathrm{P}$, and $\mathrm{T}$ stand for the corresponding state and phase parameters. 
Table S5. The relationship between cycling performance and current density as well as discharge depth with a CRF1500-40 cathode in the oxygen environment.

\begin{tabular}{lcccccc}
\hline Cathode & $\begin{array}{c}\text { Electrolyt } \\
\mathrm{e}\end{array}$ & $\begin{array}{c}\text { Carbo } \\
\mathrm{n} \\
\text { loadin/ } \\
\mathrm{mg}\end{array}$ & $\begin{array}{c}\text { Current } \\
\text { density/m } \\
\mathrm{A} \mathrm{cm}^{2}\end{array}$ & $\begin{array}{c}\text { Specific } \\
\text { capacity/ } \\
\mathrm{mAh} \mathrm{g}^{-1}\end{array}$ & $\begin{array}{c}\text { Capacity } \\
/ \mathrm{mAh}\end{array}$ & $\begin{array}{c}\text { Cycling } \\
\text { number }\end{array}$ \\
\hline & & & 0.05 & 1000 & 0.4 & 100 \\
& & & 0.1 & 1000 & 0.4 & 112 \\
$\mathrm{CRF1500-}$ & $1 \mathrm{M}$ & & 0.1 & 1500 & 0.6 & 44 \\
$40+\mathrm{pVdF}=$ & LiTFSI/ & 0.4 & 0.1 & 2000 & 0.8 & 34 \\
$9: 1$ & sulfolane & & 0.3 & $2000 / 1000$ & $0.8 / 0.4$ & $24 / 94$ \\
& & & 0.4 & $4000 / 1000$ & $1.2 / 0.4$ & $10 / 64$ \\
& & & 0.5 & $5000 / 1000$ & $1.6 / 0.4$ & $3 / 56$ \\
& & & 1.0 & $10000 / 1000$ & $4.0 / 0.4$ & $1 / 18$ \\
\hline
\end{tabular}

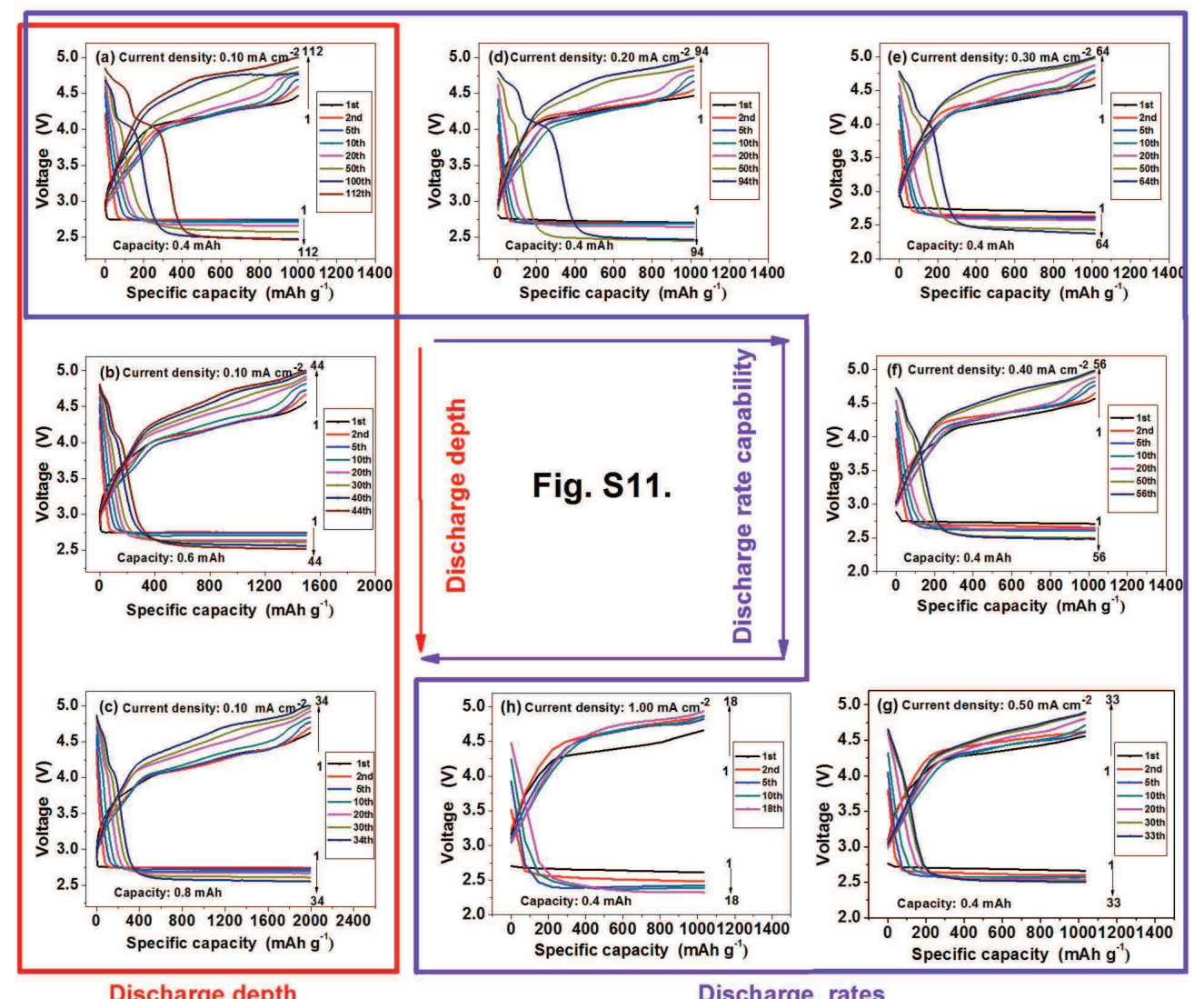

Fig. S11. Discharge-charge curves of the lithium-air batteries with a CRF1500-40 carbon cathode at various current densities and discharge depth of different cycles. $1 \mathrm{M}$ LiTFSI/sulfolane is used as electrolyte and the carbon loading is $0.4 \mathrm{mg}$. Current density and specific capacity are noted as below: 
(a) $0.10 \mathrm{~mA} \mathrm{~cm}^{-2}, 1000 \mathrm{mAh} \mathrm{g}^{-1}$; (b) $0.10 \mathrm{~mA} \mathrm{~cm}{ }^{-2}, 1500 \mathrm{mAh} \mathrm{g}^{-1}$; (c) $0.10 \mathrm{~mA} \mathrm{~cm}{ }^{-2}, 2000 \mathrm{mAh} \mathrm{g}^{-1}$;

(d) $0.20 \mathrm{~mA} \mathrm{~cm}^{-2}, 1000 \mathrm{mAh} \mathrm{g}^{-1}$; (e) $0.30 \mathrm{~mA} \mathrm{~cm}^{-2}, 1000 \mathrm{mAh} \mathrm{g}^{-1}$; (f) $0.40 \mathrm{~mA} \mathrm{~cm}{ }^{-2}, 1000 \mathrm{mAh} \mathrm{g}^{-1}$;

(g) $0.50 \mathrm{~mA} \mathrm{~cm}{ }^{-2}, 1000 \mathrm{mAh} \mathrm{g}^{-1}$; (h) $1.00 \mathrm{~mA} \mathrm{~cm}^{-2}, 1000 \mathrm{mAh} \mathrm{g}^{-1}$.

It is worth mentioning that each carbon paper cathode had a mass of $26.4 \pm 2 \mathrm{mg}$, which was about 250 times higher than $0.1 \mathrm{mg}$ of the carbon loading described below. Therefore, it actually contributed less than $4 \mathrm{mAh} \mathrm{g}^{-1}$ specific capacity to the whole lithium air battery. In addition, more coating would lead to cathode pore blockage and deterioration of cycling performance, which was inconsistent with the experimental results. This strongly suggested that carbon aerogel was an effective electro-active material.

To construct a practical applied lithium-air battery, all the galvanostatic charge-discharge tests were simultaneously conducted in a long period of time $(\geqq 2.3 \mathrm{~h})$. Particularly, for a perspicuous comparison, the testing time was fixed to 2.3 hours when the current density increased to $0.20 \mathrm{~mA}$ $\mathrm{cm}^{-2}$ or above. This discharge time comes from the case of a current density of $0.1 \mathrm{~mA} \mathrm{~cm}$ and specific capacity of $1000 \mathrm{mAh} \mathrm{g}^{-1}$ (see I in the below ). Therefore, the discharge specific capacity differed from each other, ranging from 1000 to $5000 \mathrm{mAh} \mathrm{g}^{-1}$ unequally (see Table S5, Fig. 4(b), Fig. S11 and Fig. S12). All the cycling number was recorded under the cut off voltage of $5.0 \mathrm{~V}$ (for charge) or $2.0 \mathrm{~V}$ (for discharge). As is shown in Fig. S12, it revealed fast cycling performance deterioration at

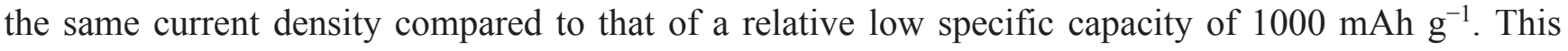
further demonstrated deep discharge was detrimental for the realization of highly rechargeable lithiumair batteries, consistent with the lithium-ion batteries. Meanwhile, high discharge rates also cause sharp recession of cycling performance.

Discharge time $=0.4 /(0.1 * 3.14 * 1.5 * 1.5 * 0.25)=2.3 \mathrm{~h}$

Note: Aerogel loading: $0.4 \mathrm{mg}$; Current density: $0.10 \mathrm{~mA} \mathrm{~cm}{ }^{-2}$; Cathode diameter (d): $1.5 \mathrm{~cm}$; $\mathrm{S}=1 / 4 \pi \mathrm{d}^{2}$ 

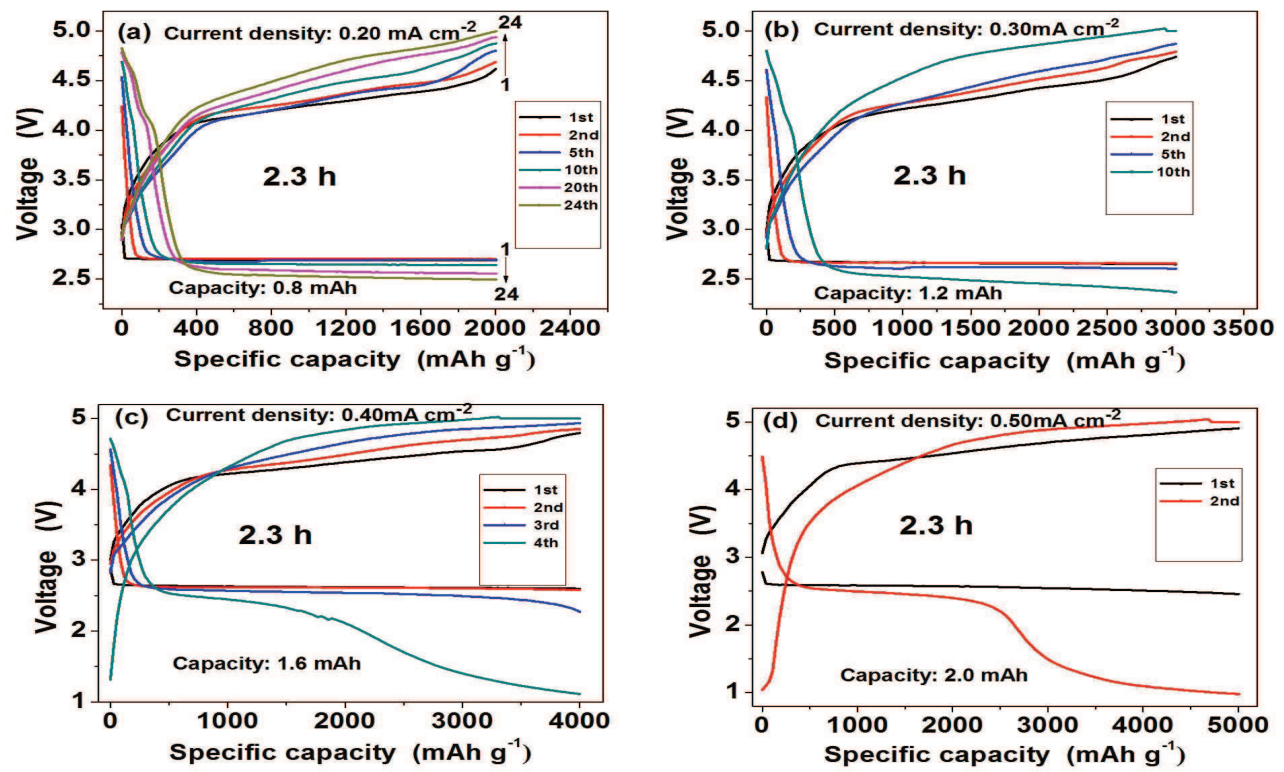

Fig. S12. Discharge-charge curves of the lithium-air batteries with CRF1500-40 carbon cathode at various current densities of different cycles. $1 \mathrm{M} \mathrm{LiTFSI/sulfolane} \mathrm{was} \mathrm{used} \mathrm{as} \mathrm{electrolyte;} \mathrm{the} \mathrm{current}$ density and specific capacity were described as below: (a) $0.20 \mathrm{~mA} \mathrm{~cm}^{-2}, 2000 \mathrm{mAh} \mathrm{g}^{-1}$; (b) $0.30 \mathrm{~mA}$ $\mathrm{cm}^{-2}, 3000 \mathrm{mAh} \mathrm{g}^{-1}$; (c) $0.40 \mathrm{~mA} \mathrm{~cm}{ }^{-2}, 4000 \mathrm{mAh} \mathrm{g}^{-1}$; (d) $0.50 \mathrm{~mA} \mathrm{~cm}^{-2}, 5000 \mathrm{mAh} \mathrm{g}^{-1}$.

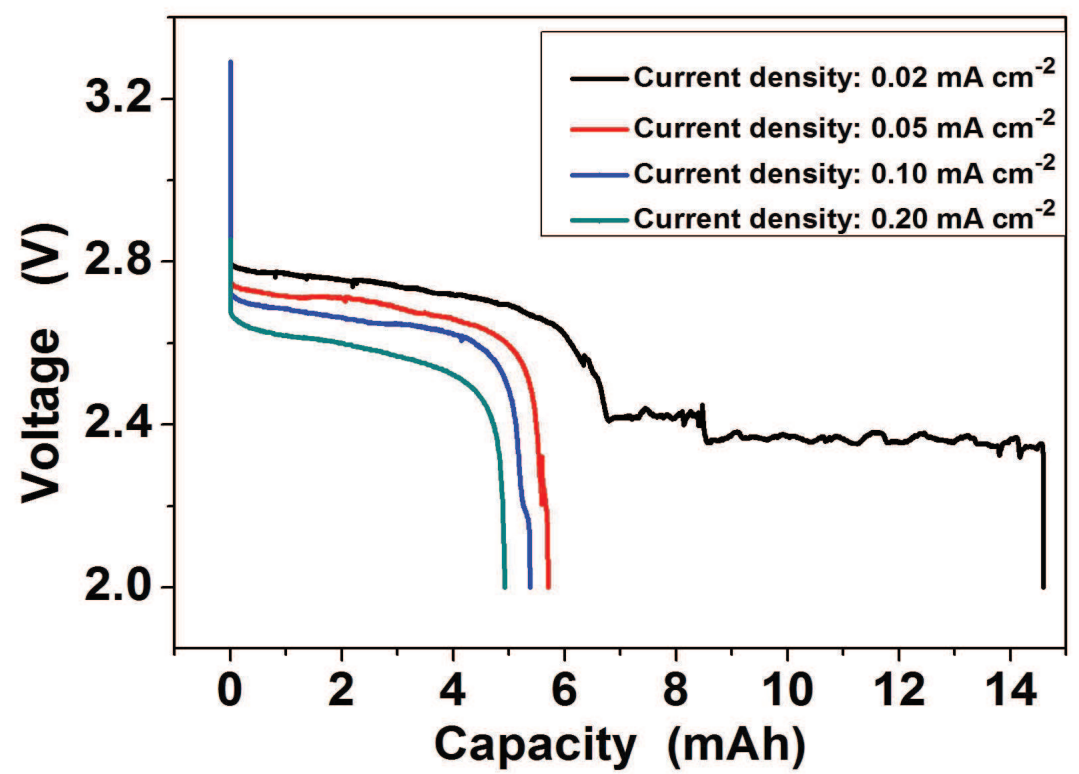

Fig. S13. Discharge curves of the lithium-air batteries with CRF1500-40 carbon cathode at various current densities in the first cycle. 


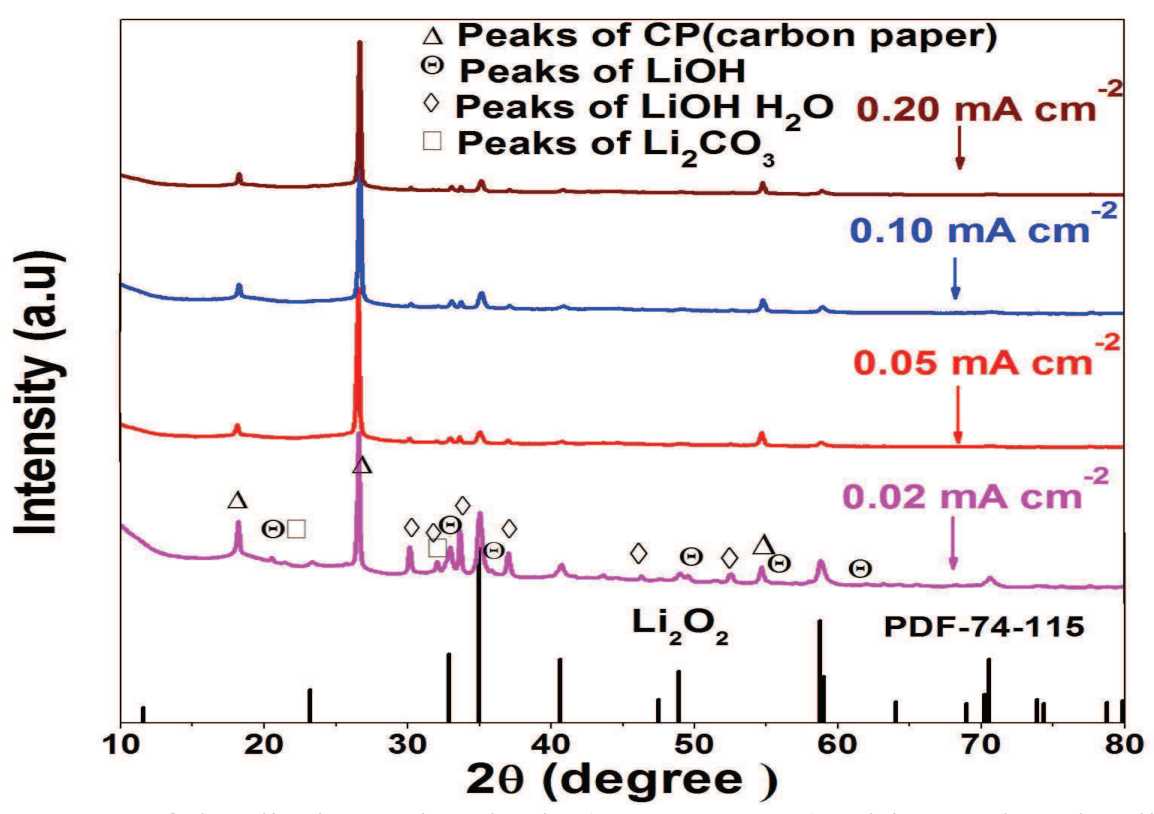

Fig. S14. XRD patterns of the discharged cathode (CRF1500-40) with a carbon loading of $0.4 \mathrm{mg}$ after 1st cycle. The current density varied from $0.02 \mathrm{~mA} \mathrm{~cm}^{-2}$ to $0.20 \mathrm{~mA} \mathrm{~cm}^{-2}$, corresponding to discharge state of Fig. S13, respectively. The discharged products agree well with the PDF 74-115 of the crystalline lithium peroxide, and PDF76-1074, PDF85-0736 and PDF83-1454 of the parasitic reaction products for $\mathrm{LiOH} \mathrm{H}_{2} \mathrm{O}$, $\mathrm{LiOH}$ and $\mathrm{Li}_{2} \mathrm{CO}_{3}$, respectively, most of which disappear after the corresponding charging process. 

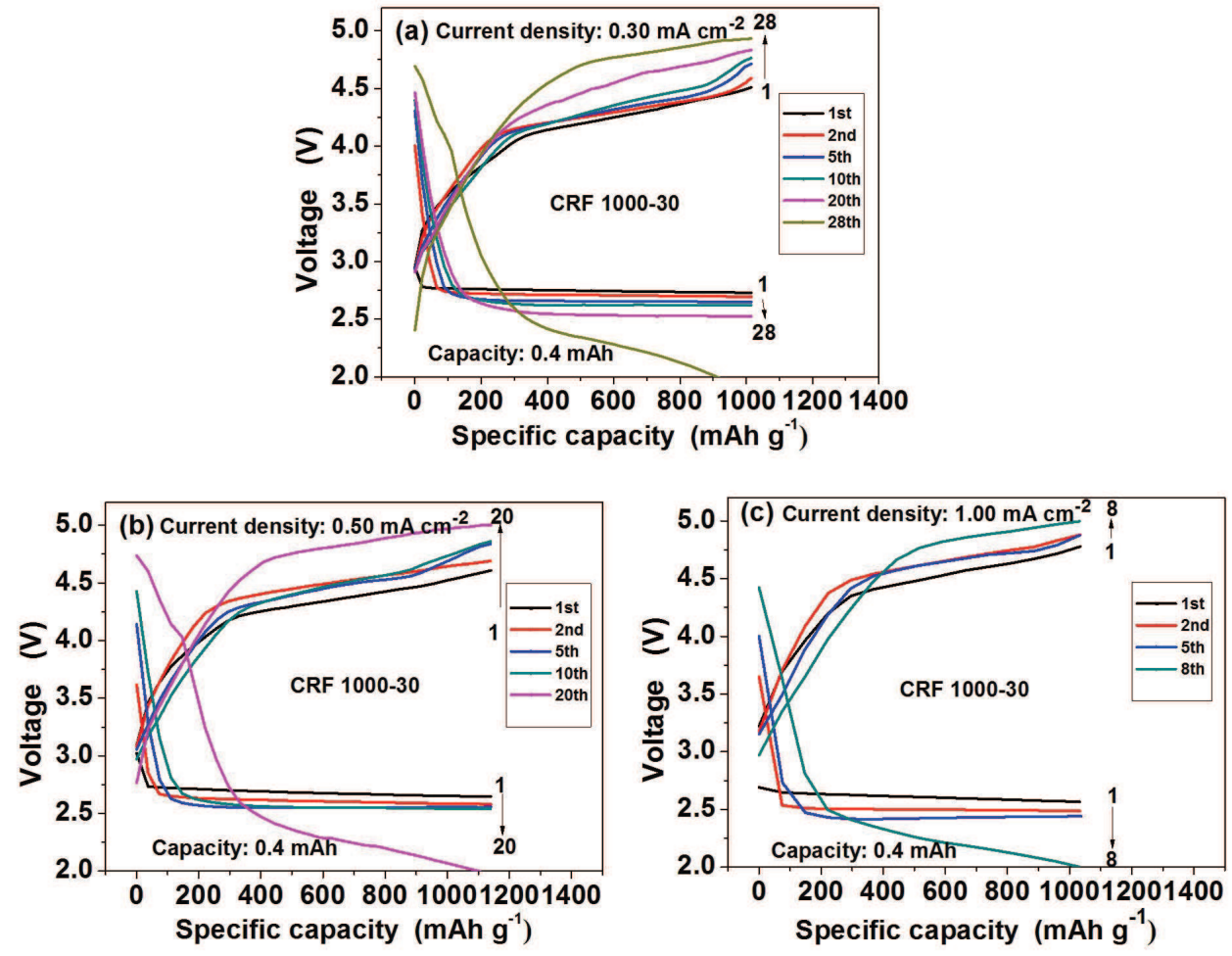

Fig. S15. Discharge-charge curves of lithium-air batteries with CRF1000-30 air cathode at various current densities of different cycles. $1 \mathrm{M} \mathrm{LiTFSI/sulfolane} \mathrm{is} \mathrm{used} \mathrm{as} \mathrm{electrolyte.} \mathrm{The} \mathrm{current} \mathrm{density}$ and specific capacity are described as below: (a) $0.30 \mathrm{~mA} \mathrm{~cm}{ }^{-2}, 1000 \mathrm{mAh} \mathrm{g}^{-1}$; (b) $0.50 \mathrm{~mA} \mathrm{~cm}^{-2}$, $1000 \mathrm{mAh} \mathrm{g}^{-1}$; (c) $1.00 \mathrm{~mA} \mathrm{~cm}{ }^{-2}, 1000 \mathrm{mAh} \mathrm{g}^{-1}$.

Table S6. The relationship between cycling performance and current density with a CRF1500-40 cathode in the air environment.

\begin{tabular}{lcccccc}
\hline Cathode & $\begin{array}{c}\text { Electrolyt } \\
\mathrm{e}\end{array}$ & $\begin{array}{c}\text { Carbon } \\
\text { loading/ } \\
\mathrm{mg}\end{array}$ & $\begin{array}{c}\text { Current } \\
\text { density/ } \\
\mathrm{mA} \mathrm{cm}^{-2}\end{array}$ & $\begin{array}{c}\text { Specific } \\
\text { capacity / } \\
\mathrm{mAh} \mathrm{g}^{-1}\end{array}$ & $\begin{array}{c}\text { Capacity } \\
\text { / mAh }\end{array}$ & $\begin{array}{c}\text { Cycling } \\
\text { number }\end{array}$ \\
\hline CRF1500- & $1 \mathrm{M}$ & 0.4 & 0.05 & 1000 & 0.4 & 40 \\
$40+\mathrm{pVdF}=$ & $\begin{array}{c}\text { LiTFSI } \\
\text { Sulfolane }\end{array}$ & & 0.1 & 1000 & 0.4 & 48 \\
\hline$: 1$ & & 0.2 & 2000 & 0.8 & 8 \\
\hline
\end{tabular}



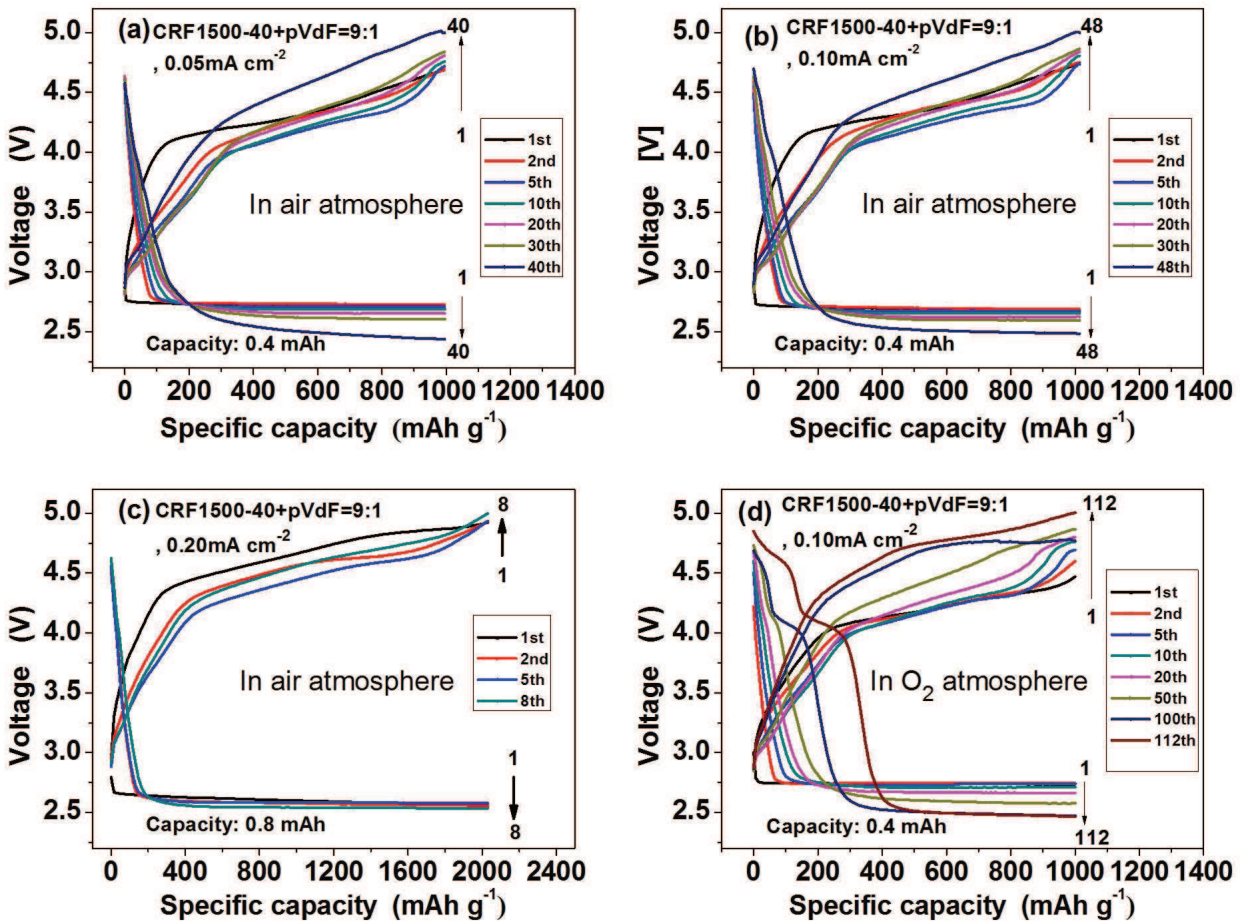

Fig. S16. Discharge-charge curves of the lithium-air batteries with CRF1500-40 air cathode at various current densities of different cycles in the air environment (a, b, c) and oxygen environment (d). $1 \mathrm{M}$ LiTFSI/sulfolane is used as electrolyte. The current density and specific capacity are described as below: (a) $0.05 \mathrm{~mA} \mathrm{~cm}{ }^{-2}, 1000 \mathrm{mAh} \mathrm{g}^{-1}$; (b,d) $0.10 \mathrm{~mA} \mathrm{~cm}{ }^{-2}, 1000 \mathrm{mAh} \mathrm{g}^{-1}$; (c) $0.20 \mathrm{~mA} \mathrm{~cm}{ }^{-2}, 2000$ $\mathrm{mAh} \mathrm{g}^{-1}$. 